Boise State University

ScholarWorks

Civil Engineering Faculty Publications and

Presentations

Department of Civil Engineering

$12-1-2018$

Understanding Track Substructure Behavior: Field Instrumentation Data Analysis and Development of Numerical Models

Huseyin Boler

University of Illinois

Debakanta Mishra

Boise State University

Wenting Hou

University of Illinois

Erol Tutumluer

University of Illinois

This is an author-produced, peer-reviewed version of this article. (C) 2018, Elsevier. Licensed under the Creative Commons Attribution-

NonCommercial-NoDerivatives 4.0 license. The final, definitive version of this document can be found online at Transportation Geotechnics, doi: 10.1016/j.trgeo.2018.10.001 


\section{Understanding Track Substructure Behavior: Field Instrumentation Data Analysis and Development of Numerical Models}

Huseyin Boler ${ }^{1}$

Debakanta Mishra, Ph.D., P.E. ${ }^{2^{\star}}$

Wenting $\mathrm{Hou}^{1}$

Erol Tutumluer, Ph.D. ${ }^{1}$

${ }^{1}$ University of Illinois, Urbana-Champaign, USA

${ }^{2}$ Boise State University, USA

* Corresponding Author; E-Mail: debmishra@boisestate.edu; Tel: (208) 426-3710; 1910

University Drive, Mail Stop 2060, Boise, Idaho, 83725-2060 


\title{
Understanding Track Substructure Behavior: Field Instrumentation Data Analysis and Development of Numerical Models
}

\begin{abstract}
Numerous studies have targeted using numerical modeling, field instrumentation, or combinations of both to gain insight into track substructure behavior under loading. In-depth understanding of track substructure behavior serving both passenger and freight trains is critical to developing suitable design and maintenance/rehabilitation methods to ensure adequate performance under loading. This manuscript presents findings from a recently completed study involving advanced instrumentation and numerical modeling to investigate track substructure-related issues at several problematic railroad bridge approaches in the United States. Multi-Depth Deflectometers (MDDs) were installed to measure transient as well as plastic deformations experienced by track substructure layers under loading. Strain gauges were installed on the rail web to measure the vertical wheel loads applied during train passage. Data from the field instrumentation was used to make inferences regarding the relative contributions of different substructure layers towards the differential movement problem. A 3-D Finite Element (FE) model was developed to further understand the behavior of the instrumented locations, and was calibrated using the field instrumentation data. An elastic layered track analysis program, GEOTRACK, was first used to iteratively backcalculate individual track substructure layer moduli from the field measurements; these backcalculated modulus values were subsequently used in the FE model to predict track response under transient loading conditions. Modulus values estimated for the ballast layer were found to be significantly affected by the presence of gaps at the tie-ballast interface at track transitions. Once validated, the model was further modified to match transient displacement results acquired in the field using a quasi-static moving load approach. Good agreement was found between the model predictions and field instrumentation results. Development of advanced numerical models augmented by field instrumentation data can facilitate the design and maintenance of well-performing track structures.
\end{abstract}

Keywords: Field Instrumentation, Multidepth Deflectometers (MDDs); GEOTRACK; Railroad Track Substructure; Finite Element Method 


\section{INTRODUCTION}

In-depth understanding of railroad track behavior under train loading can be achieved through the development and adoption of state-of-the-art modeling and analysis methods. Numerous research studies over the years have focused on the development of advanced layered track analysis models. Traditional analysis and design methods generally utilize concepts such as Beam on Elastic Foundation (BOEF), and Elastic Layered Theory (ELT), whereas modern analysis approaches often take advantage of advanced numerical methods such as the Finite Element Methods (FEMs). Although track analysis models based on the concept of FEM are often capable of analyzing complex geometries and material properties, they must still be associated with certain simplifying assumptions in terms of material behavior and boundary conditions. Accordingly, to improve the accuracy of model predictions, these models often need to be calibrated and validated against track response values or transient responses under train loading measured through field instrumentation efforts.

Although several studies have used advanced instrumentation methods to measure track response under loading, these approaches have primarily focused on recording track surface responses using accelerometers, strain gauges, and/or Linear Variable Differential Transformers (LVDTs). The primary advantage of such instrumentation is that they are easy to install, and are often non-intrusive (or non-invasive) in nature. However, their main limitation is that they measure track response at the surface only, and therefore fail to adequately account for different substructure conditions, and discontinuities in the track system such as those introduced by gaps underneath the ties. Therefore, advanced numerical models created and calibrated using results obtained through such instrumentation efforts only focus on total track displacements or accelerations measured/predicted at the track surface without giving due consideration to the effects of individual substructure layers and components.

Instrumentation approaches with the ability to measure track responses at different depths can present a significant improvement over traditional instruments installed at the surface. One such procedure for measuring displacements (both elastic/resilient and plastic/permanent) to varying depths within the track substructure layers involves the use of Multi-Depth Deflectometers (MDD) (Gräbe and Shaw 2010; Scullion et al. 1989). Track response data obtained from MDDs can thus present enhanced capabilities for calibration and validation of numerical models developed for track substructure analysis under loading. This manuscript discusses findings from a recently completed study where advanced field instrumentation and numerical modeling were used to acquire an in-depth understanding of track substructure and track transition behavior.

\section{OBJECTIVE AND SCOPE}

The primary objective of this research effort was to gain an in-depth understanding of track substructure behavior under transient loading through combined usage of field instrumentation and numerical modeling. The use of MDDs and interpretation of the measured data is presented as an efficient approach to aid the numerical model development; as the measurement of 
vertical deformations at different depths within the track substructure can help to establish the modulus values for individual layers. The scope of this paper therefore covers first how modulus values for individual track substructure layers can be iteratively backcalculated using a validated layered-elastic analysis program, such as GEOTRACK (Chang et al. 1980). A close look at the layer modulus values estimated from analysis of MDD data indicated that the presence of gaps at the tie-ballast interface could lead to unreasonably low estimated modulus. The modified track substructure layer modulus values calculated after accounting for the gap at the tie-ballast interface were the needed inputs in a newly developed 3-D FEM model validated with the measured track response under loading. The scope further covers the application of the 3-D FE model to study the track substructure response under a simulated moving wheel load. The detailed results from the 3-D FE model are presented to indicate a reasonably good representation and close predictions of track substructure behavior even if the 'true' dynamic properties of tracks were not considered in the model.

\section{INSTRUMENTATION AND MONITORING OF TRACK SUBSTRUCTURE BEHAVIOR}

A recent research study sponsored by the Federal Railroad Administration (FRA) in the US focused on instrumentation and performance monitoring of track transitions such as bridge approaches to investigate different factors contributing to the problem of the 'bump at the end of the bridge.' MDDs and strain gauges were installed at three railway bridge approaches along Amtrak's Northeast Corridor (NEC) near Chester, Pennsylvania. Although the instrumentation was carried out at track transitions, this paper primarily focuses on the aspect of track substructure behavior and how in-depth understanding of track substructure behavior can be facilitated by combining field instrumentation and numerical modeling. Monitoring of the instrumented bridge approaches over a four-year period identified the ballast layer to be the primary contributor towards the overall track substructure deformations (both elastic or resilient as well as plastic or permanent components). This observation led to the implementation of several remedial measures to "stabilize" the ballast layer and reduce the elastic as well as plastic deformations. Further details about this study and its findings can be found elsewhere (Mishra et al. 2016; Mishra et al. 2014a; Mishra et al. 2014b; Mishra et al. 2012; Tutumluer et al. 2012). The following sections of this manuscript focus on how suitably selected data filters can be used to extract pertinent information from field instrumentation data.

\subsection{Data Filtering to Extract Relevant Information}

Transient response data collected at the instrumented bridge approaches under train loading include a variety of information related to train loading geometry, effects from wheel or rail defects, noise from Alternating Current (AC), or other signal noise introduced due to imperfections in the instrumentation and data collection circuits. This makes the analysis of the unfiltered acquired data prohibitively difficult. Two common approaches can be adopted to eliminate/reduce the noise associated with any data collection activity. The first approach involves the elimination of noise through the use of algorithms and filters built into the data acquisition equipment. Although this approach can be quite effective and can greatly simplify data post-processing and analysis efforts, data acquisition equipment comprising filtering capabilities can be significantly expensive. Therefore, a more commonly used approach to 
eliminate/reduce noise from field data involves the use of digital signal processing techniques during data post-processing. Selection of appropriate filters can often eliminate unwanted noise, and thus generating a signal containing primarily the information of interest.

Selection of this appropriate digital filter, however, requires diligent effort since choosing the wrong digital filter could potentially eliminate crucial information. To prevent elimination of critical information, the frequency of interest of a digital signal (transient displacement time history in this case) must be determined, and content outside of this interested frequency range must be eliminated. One of the most common approaches to identify different contributing waveforms in a signal involves the use of Fourier transform to convert the data from time domain to frequency domain. An example case illustrating the frequency domain representation of transient displacements recorded by the top-most LVDT in an MDD string is presented in Figure 1. Note that the data presented in Figure 1 was collected at the Near-Bridge Location (3.7-m from the bridge abutment) at the Madison Street bridge approach near Chester, Pennsylvania. More details about these sites can be found elsewhere (Mishra et al. 2016; Mishra et al. 2014a; Mishra et al. 2014b). As seen in the figure, a significant portion of the peaks resides below 20 $\mathrm{Hz}$.

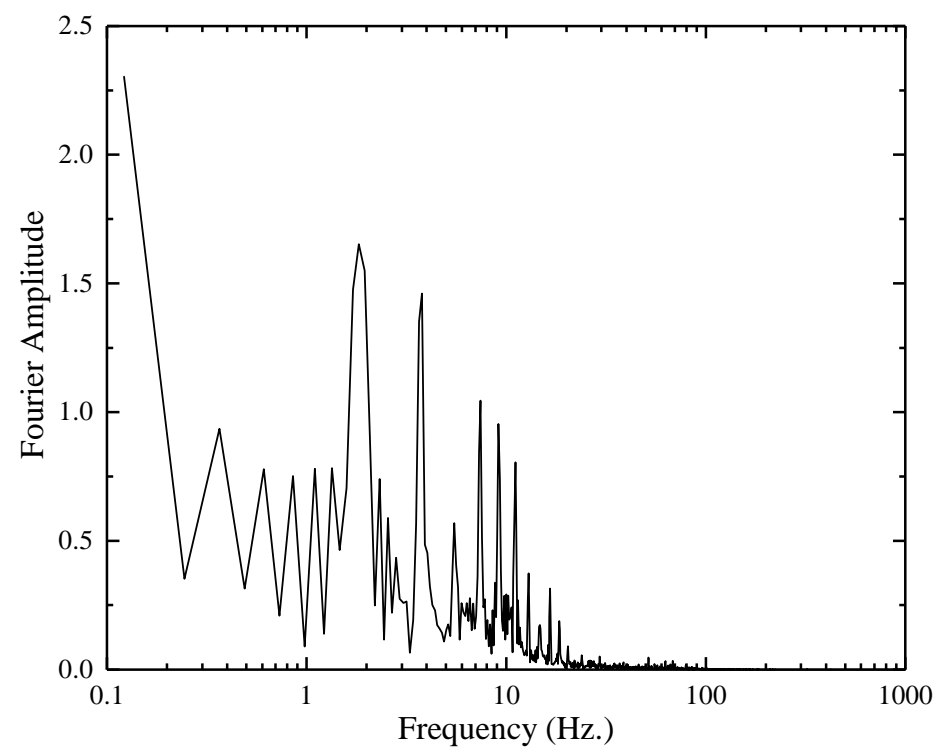

Figure 1: Example Representation of Ballast Transient Deformation Time History in Frequency Domain (Data Presented for Madison Street; Near Bridge Location; June 2013)

Several researchers in the past have relied on frequency domain analysis of load-displacement time history to make inferences about track behavior. Auersch (2006) reported that vibrations due to wheel passage were not observed at frequencies over $50 \mathrm{~Hz}$; any vibrations observed at frequencies between $50 \mathrm{~Hz}$ and $125 \mathrm{~Hz}$ could be related to wheel and rail anomalies. After optical measurement of railway track displacements under a train moving at $220 \mathrm{~km} / \mathrm{h}$, Namura and Suzuki (2007) stated that unsupported sleeper information could be discovered using train axle acceleration and that they corresponded to frequencies between $10 \mathrm{~Hz}$ to $20 \mathrm{~Hz}$. Priest et al. (2010) observed that dominant ground velocities obtained from geophone measurements 
under the passage of a coal train moving at $50 \mathrm{~km} / \mathrm{h}$ corresponded to frequencies around 1, 2, and $6 \mathrm{~Hz}$, and concluded that the frequencies correspond to axle spacings and distance between consecutive bogies. Paixão et al. (2015) used an $80 \mathrm{~Hz}$ low pass filter to eliminate any noise caused by wheel and track defects for conveniently analyzing displacements obtained from field measurements. Pinto et al. (2015) used an optical monitoring system to measure the vertical transient displacement of a track section under the passage of train with a speed of 220 $\mathrm{km} / \mathrm{h}(61.11 \mathrm{~m} / \mathrm{sec})$. They applied Fourier transform to transient displacement time history and determined a significant portion of the content to be below $30 \mathrm{~Hz}$. They indicated that results depended on train signature or geometry such as axle spacing and train speed. Several researchers (Auersch 2006; Degrande and Lombaert 2000; Galvin et al. 2010; Kouroussis et al. 2015b; Kouroussis et al. 2016; Kouroussis et al. 2015e; Ling et al. 2010; Lombaert et al. 2006) have utilized train geometry information (axle, bogie, carriage spacing) and train speed to analyze transient data they either obtained from the field or numerical analyses. Kouroussis et al. (2015c); Kouroussis et al. (2015d) developed a methodology to determine train speed by using dominant frequency content obtained from field vibration measurements and train geometry information.

Considering these studies and the results presented in Figure 1, the current research effort utilized the geometry of predominant train types on the instrumented track to identify relevant frequency content for analysis. Relevant axle and wheel spacing data for the Acela Express trains on US Amtrak's NEC are presented in Figure 2.

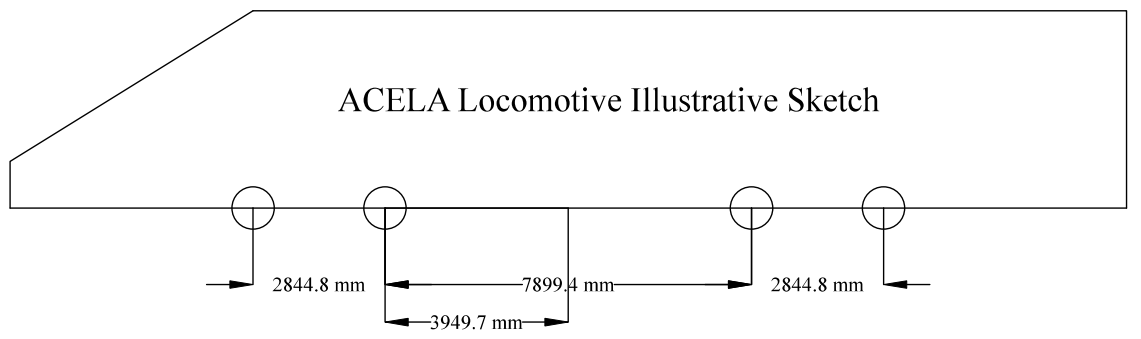

a) ACELA Locomotive Illustrative Sketch

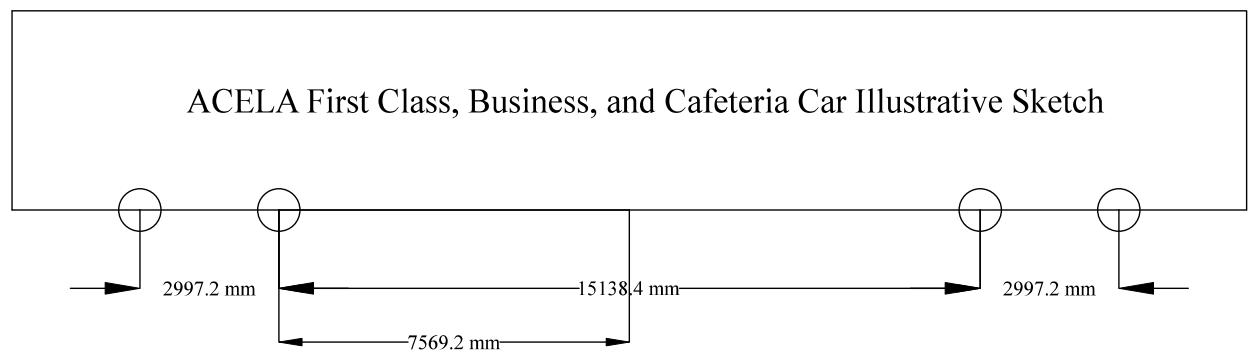

b) First Class, Business Class, and Cafeteria Car Illustration

Figure 2: ACELA Locomotive and Passenger Cars Axle Spacing

Although the maximum operating speed for an ACELA Express train along Amtrak's NEC is 241 $\mathrm{km} / \mathrm{h}$ (150 mph), the operating speed near the instrumented bridge approaches is $177 \mathrm{~km} / \mathrm{h}$ (110 mph or $49.17 \mathrm{~m} / \mathrm{sec}$ ). The frequency of interest for a specific spacing is calculated using 
the train speed and the spacing value. For instance, the minimum distance of interest during the passage of an ACELA Express train is $2.85 \mathrm{~m}$, which represents the distance between two wheels attached to a bogie of the locomotive. The maximum frequency of interest is thus calculated using following equation.

$$
f=\frac{v}{d}=\frac{49.17}{2.85}=17.25 \mathrm{~Hz}
$$

The corresponding frequencies for each spacing type are calculated and presented in Table 1. As seen in the table and computed in the equation, the maximum frequency of interest during the passage of an Acela Express train over the instrumented bridge approaches is $17.25 \mathrm{~Hz}$. Any frequency content above that frequency does not contribute to transient displacements. To address slight possible increase in the operating speeds (although unlikely), data analysis efforts in the current study focused on all frequencies lower than $20 \mathrm{~Hz}$. To isolate all information pertaining to signals with a frequency of $20 \mathrm{~Hz}$ from the recorded displacement time histories, a 30-Hz 6-pole Butterworth (Butterworth 1930) low pass filter was applied to all transient displacement data. The magnitude multiplier at different frequencies for this particular filter has been plotted in Figure 3. As seen from the figure, this low-pass filter retains all signal information corresponding to frequency levels below $20 \mathrm{~Hz}$ (indicated by a magnitude multiplier value of 1.0). Therefore, use of this signal filter is justified for use during the analyses of transient response data from the Amtrak NEC bridge approaches.

Table 1: ACELA Express Train Spacing and Corresponding Frequencies

\begin{tabular}{|l|l|l|}
\hline Spacing Type & Spacing Amount (m) & $\begin{array}{l}\text { Corresponding } \\
\text { Frequency (Hz) }\end{array}$ \\
\hline Locomotive Axle & 2.85 & 17.25 \\
\hline Carriage Car Axle & 3.0 & 16.39 \\
\hline Locomotive Bogie & 10.74 & 4.58 \\
\hline Carriage Car Bogie & 15.14 & 3.25 \\
\hline Adjacent Bogie Axles (Locomotive to Car) & 6.675 & 7.37 \\
\hline Adjacent Bogie Axles (Between Cars) & 5.74 & 8.56 \\
\hline Between Carriages (Car to Car) & 23.88 & 2.06 \\
\hline Between Carriages (Locomotive to Car) & 22.54 & 2.18 \\
\hline
\end{tabular}




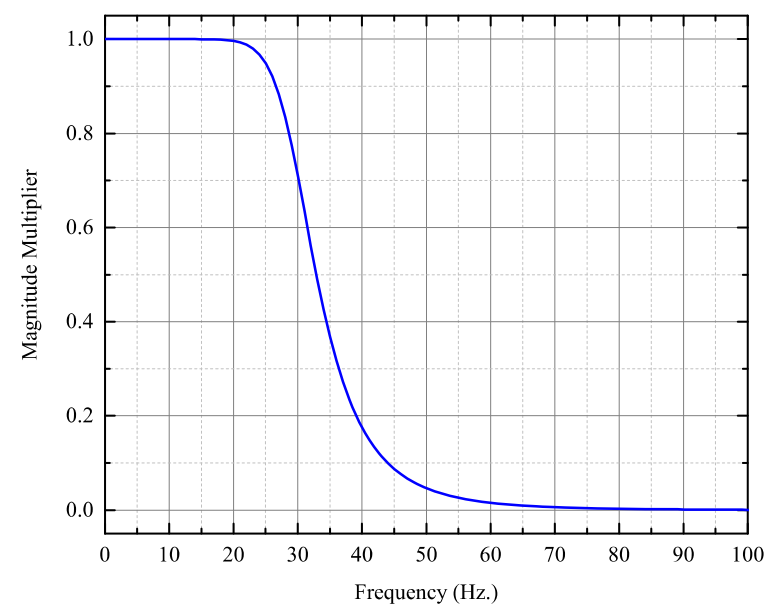

Figure 3: Magnitude Multipliers Corresponding to Different Frequencies for a 30-Hz 6Pole Low Pass Butterworth Filter

Figure 4 illustrates the effect of this filter on computed vertical accelerations. The data presented in Figure 4 corresponds to the Near-Bridge Location (NBL) at the Madison Street bridge approach. Further details about this site can be found elsewhere (Mishra et al. 2016; Mishra et al. 2014a; Mishra et al. 2014b). Two computed vertical acceleration time histories are displayed: one computed from an unfiltered transient displacement time history and one computed from a filtered transient displacement time history. While the first trend contains too much information (both relevant and unrelated to this research study), it is impossible to analyze and make conclusions. However, it is entirely possible to analyze and make conclusions from the second trend. Therefore, the use of this signal filter is justified for use during the analyses of transient response data from Amtrak NEC bridge approaches. Once the data have been filtered, it can be used to extract relevant information about the transient response of the track under loading. Besides drawing inferences regarding the relevant contributions of different track substructure layers towards the total transient deformations under loading, field instrumentation data thus obtained, can also be used to estimate the modulus values for individual track substructure layers. 

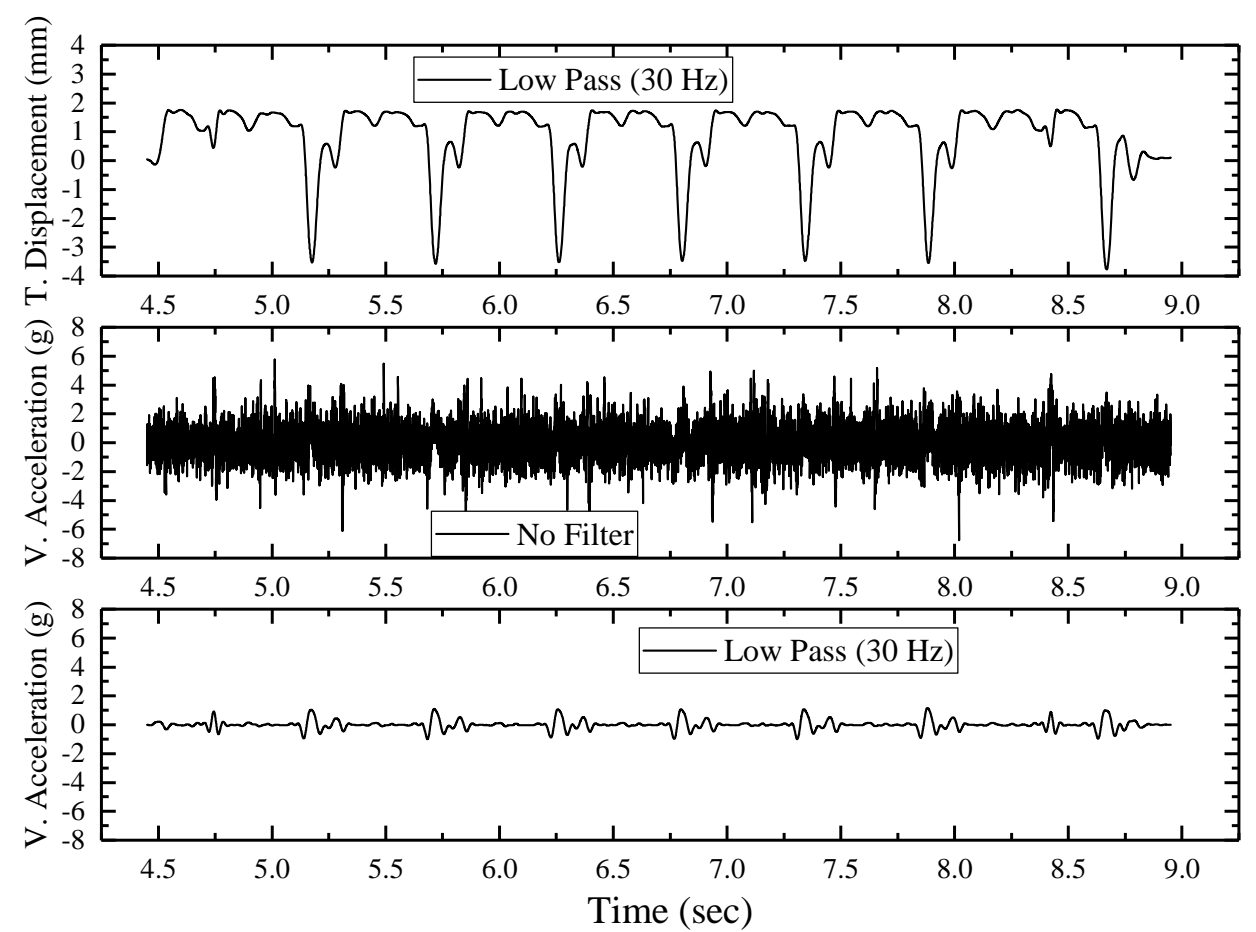

Figure 4: Computed Vertical Accelerations from Unfiltered and Filtered Transient Displacement Data (Madison Street; Near Bridge Location; Time History form Top-Most LVDT)

\section{ESTIMATING TRACK SUBSTRUCTURE LAYER MODULUS FROM DISPLACEMENT TIME HISTORIES}

Transient displacement time histories obtained from the MDDs can be used to estimate the modulus values for individual track substructure layers. Besides giving a detailed insight into track substructure behavior, this can also facilitate the development of representative numerical models for track analysis. Although the mechanical properties of rails, concrete crossties, etc. remain relatively unchanged from one track location to the other (provided the material types remain unchanged), properties of the substructure layers can change significantly. One of the most challenging tasks in the modeling of railway track structures usually involves assigning appropriate properties to track substructure layers. Properties assigned to individual track substructure layers are often based on laboratory testing of collected samples, which itself is not very easy to accomplish. Moreover, when variabilities associated with sampling and testing techniques are considered, the laboratory-established results may not be representative of actual field conditions. Measurement of transient deformations at different depths within the track substructure can help overcome this problem significantly.

The MDDs used in the current study were capable of providing transient deformation data at different depths and could be used along with a track analysis program to iteratively estimate the individual layer modulus values. It is important to note that this is possible only if the track transient deformation values measured are representative of the individual layer deformations; 
this was accomplished in the current study by installing the individual MDD modules at the substructure layer interfaces. Figure 5 shows the substructure layer profiles established at the Madison and Upland Street bridge approaches (both near-bridge and open-track locations). As shown in the figure, the MDD modules were installed at the layer interfaces; the transient deformations recorded were, therefore, representative of the individual substructure layers. Further details about the instrumentation approach can be found elsewhere (Mishra et al. 2014b).

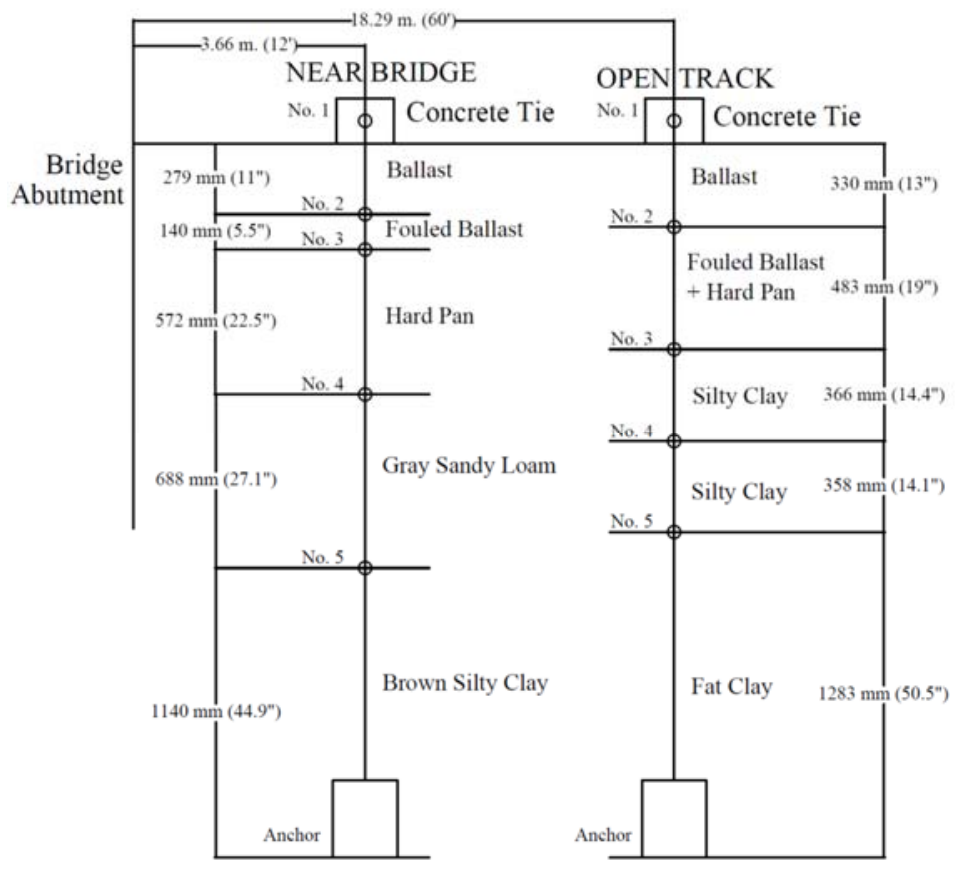

(a)

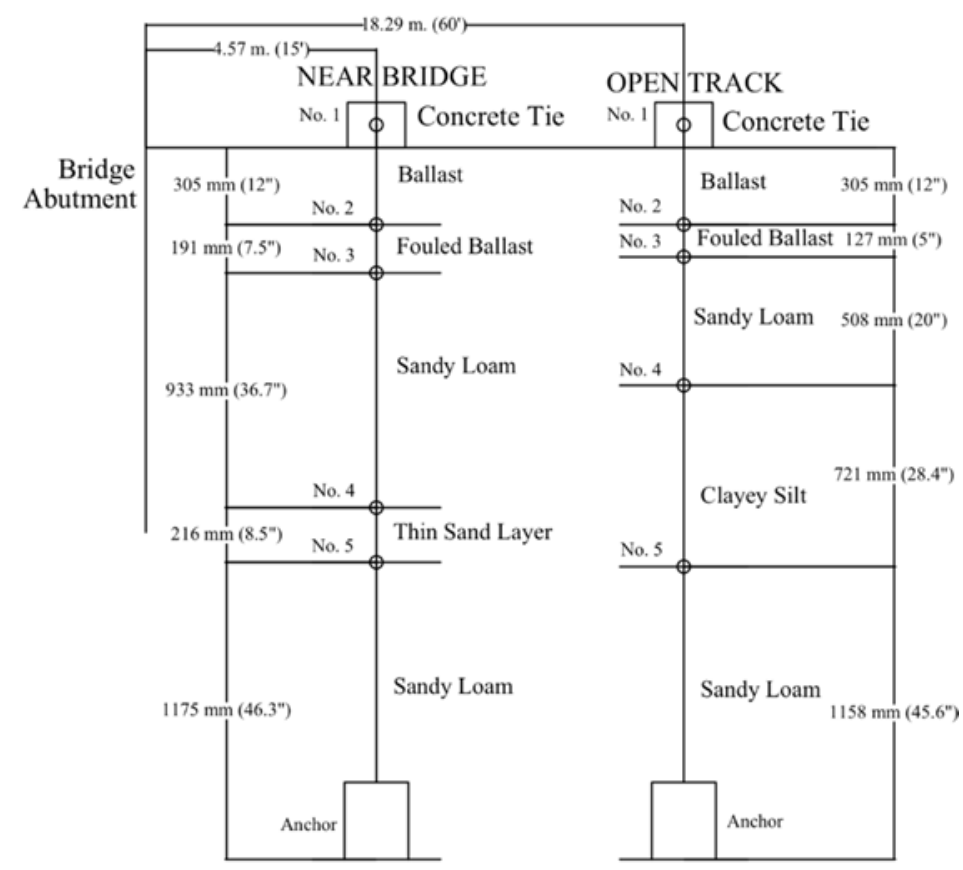

(b) 


\section{Figure 5: Track Substructure Layer Profiles Established for the Near-Bridge and Open- Track Locations at (a) Madison; and (b) Upland Street Bridge Locations}

The current study utilized GEOTRACK to estimate the modulus values of individual substructure layers using an iterative approach. GEOTRACK was originally developed by Chang et al. (1980) and was subsequently validated through studies by Stewart and Selig (1982). Based on the theory of Elastic Layered Analysis (Burmister 1943; Burmister 1945; Burmister et al. 1944), GEOTRACK allows the calculation of track deflection, track modulus, as well as stresses and displacements in the ballast, subballast, and subgrade layers. The track substructure layers can be modeled as having constant or stress-dependent resilient modulus. The rail is represented by an elastic beam supported by a number of concentrated reactions, one each at the tie-rail intersection points. Within the analysis zone, the rails span eleven ties, and are free to rotate at the ends as well as at the rail-tie supports (Chang et al. 1980; Selig and Waters 1994). The ties are also modeled as elastic beams, and rest directly on top of the ballast layer. Each tie is divided into ten equal rectangular segments with the support reaction provided by the ballast represented as concentrated forces at the center of each segment. For the sake of analysis, the tie-ballast pressure is applied on the surface of the ballast layer in the form of a uniform pressure distributed over a circular area; size of the circular segment is calculated by setting its area equal to that of a rectangular tie segment (after dividing the tie to ten equal segments). The connection between the rail and tie is represented by a linear spring which can sustain both tensile as well as compressive forces. All layers are assumed to be infinite in the horizontal direction, and are placed on a semi-infinite elastic half space.

Typical track parameters used during the GEOTRACK analysis in the current study have been tabulated elsewhere (Mishra et al. 2014a). The modulus values for individual track substructure layers were established adopting an iterative approach that assigned a set of 'seed' modulus values to individual substructure layers, and calculated the elastic deformations at different depths corresponding to placement of the MDD modules. Individual layer modulus values were adjusted to minimize the difference between the measured and predicted layer deformation. This process was repeated until the measured and predicted deformation values matched within a tolerance level of less than $5 \%$. Modulus values estimated for different track substructure layers at the Madison and Upland Street bridge locations are tabulated in Table 2. 
Table 2: Track Substructure Layer Modulus Values for (a) Madison Street and (b) Upland Street Bridge Approaches Estimated through Iterative Analysis using GEOTRACK Before Correcting for Contributions due to Tie-Gaps

(a)

\begin{tabular}{|l|c|c|c|c|l|l|l|l|c|}
\hline \multicolumn{3}{|c|}{ Madison: Near-Bridge Location (MPa) } & \multicolumn{3}{c|}{ Madison: Open-Track Location (MPa) } \\
\hline Layer & $\begin{array}{l}\text { Aug } \\
\mathbf{2 0 1 2}\end{array}$ & $\begin{array}{l}\text { Nov } \\
\mathbf{2 0 1 2}\end{array}$ & $\begin{array}{l}\text { Jan } \\
\mathbf{2 0 1 3}\end{array}$ & $\begin{array}{l}\text { June } \\
\mathbf{2 0 1 3}\end{array}$ & Layer & $\begin{array}{l}\text { Aug } \\
\mathbf{2 0 1 2}\end{array}$ & $\begin{array}{l}\text { Nov } \\
\mathbf{2 0 1 2}\end{array}$ & $\begin{array}{l}\text { Jan } \\
\mathbf{2 0 1 3}\end{array}$ & $\begin{array}{l}\text { June } \\
\mathbf{2 0 1 3}\end{array}$ \\
\hline Ballast & N/A & 21 & 14 & 17 & Ballast & N/A & 29 & 28 & 25 \\
\hline $\begin{array}{l}\text { Fouled } \\
\text { Ballast }\end{array}$ & N/A & 21 & 14 & 17 & $\begin{array}{l}\text { Fouled Ballast + } \\
\text { Hard Pan }\end{array}$ & N/A & 61 & 68 & 63 \\
\hline $\begin{array}{l}\text { Hard } \\
\text { Pan }\end{array}$ & N/A & 77 & 51 & 56 & Silty Clay & N/A & 36 & 39 & 33 \\
\hline $\begin{array}{l}\text { Grey } \\
\text { Sandy } \\
\text { Loam } \\
+\end{array}$ & N/A & 34 & 24 & 26 & Silty Clay & N/A & 40 & 40 & 40 \\
\hline $\begin{array}{l}\text { Brownder } \\
\text { Silty } \\
\text { Clay }\end{array}$ & N/A & 42 & 39 & 41 & Fat Clay & N/A & 59 & 58 & 59 \\
\hline
\end{tabular}

(b)

\begin{tabular}{|l|c|c|c|c|l|c|c|c|c|}
\hline \multicolumn{4}{|c|}{ Upland: Near-Bridge Location (MPa) } & \multicolumn{3}{c|}{ Upland: Open-Track Location (MPa) } \\
\hline Layer & $\begin{array}{l}\text { Aug } \\
\mathbf{2 0 1 2}\end{array}$ & $\begin{array}{l}\text { Nov } \\
\mathbf{2 0 1 2}\end{array}$ & $\begin{array}{l}\text { Jan } \\
\mathbf{2 0 1 3}\end{array}$ & $\begin{array}{c}\text { June } \\
\mathbf{2 0 1 3}\end{array}$ & Layer & $\begin{array}{c}\text { Aug } \\
\mathbf{2 0 1 2}\end{array}$ & $\begin{array}{c}\text { Nov } \\
\mathbf{2 0 1 2}\end{array}$ & $\begin{array}{c}\text { Jan } \\
\mathbf{2 0 1 3}\end{array}$ & $\begin{array}{c}\text { June } \\
\mathbf{2 0 1 3}\end{array}$ \\
\hline Ballast & 20 & N/A & 15 & 5 & Ballast & 48 & 69 & 51 & 75 \\
\hline Fouled Ballast & 40 & N/A & 35 & 35 & $\begin{array}{l}\text { Fouled } \\
\text { Ballast }\end{array}$ & 19 & 55 & 48 & 51 \\
\hline Sandy Loam & 35 & N/A & 28 & 31 & Sandy Loam & 33 & 31.5 & 30 & 31 \\
\hline $\begin{array}{l}\text { Thin Sand } \\
\text { Layer }\end{array}$ & 55 & N/A & 55 & 55 & Clayey Silt & 38 & 32 & 31 & 32 \\
\hline Sandy Loam & 85 & N/A & 85 & 85 & \multicolumn{7}{|l|}{ Sandy Loam } & 73 & 69 & 60 & 70 \\
\hline
\end{tabular}

As seen from Table 2, the estimated modulus values for the ballast layers were consistently lower than typical values reported in the literature e.g., Sussman and Selig (2000). This is primarily because transient deformations recorded by the top-most LVDT in an MDD system comprises contributions from (1) movement of the tie before it comes in contact with the underlying ballast layer, and (2) movement of the tie-ballast system as a unit. Accordingly, taking the transient displacements recorded by the top-most LVDT as representative of the ballast layer deformation can lead to serious over-estimation of movements within the ballast layer. This, in turn, leads to significant under-estimation of the backcalculated ballast layer modulus values. 
The next step in this research effort involved quantifying the gap at the tie-ballast interface, and revised estimation of the track substructure layer modulus values after eliminating the tie-gap contributions from the transient deformation values recorded by the top-most LVDTs in the MDD system. A new approach referred to as the 'Progressive Load Threshold (PLT) Approach' was developed to quantify the gap (if any) at the tie-ballast interface.

\section{QUANTIFYING GAPS AT TIE-BALLAST INTERFACE}

The PLT Approach developed in this study to quantify the gap at the tie-ballast interface is conceptually identical to the procedure developed by Sussman and Selig (2000), and is based on the premises that the slope of the load-deflection curve changes drastically depending on whether full-contact at the tie-ballast interface has been established, or not. Closure of a gap between ballast surface and tie base requires an initial amount of wheel load before any deflection occurs in track substructure. A visual representation of this concept was presented by Li et al. (2015) and has been included in Figure 6. As illustrated in the figure, a part of the load is first consumed to establish full contact between the tie and the ballast (marked as "seating" in Figure 6). The remaining portion of the load is consumed to induce deformations in the track substructure layers. Considering that the MDD system enables recording the full time-history of transient responses under train loading, the load (recorded using strain gauges) and deflection data can be easily used to quantify the gaps underneath the instrumented ties. The PLT approach determines the gap amount under the tie by determining the initial loading from the wheel load and the deflection curve. Details regarding this approach were discussed by Boler et al. (2018); the following steps involved in the PLT approach have been listed here for the sake of completeness. 


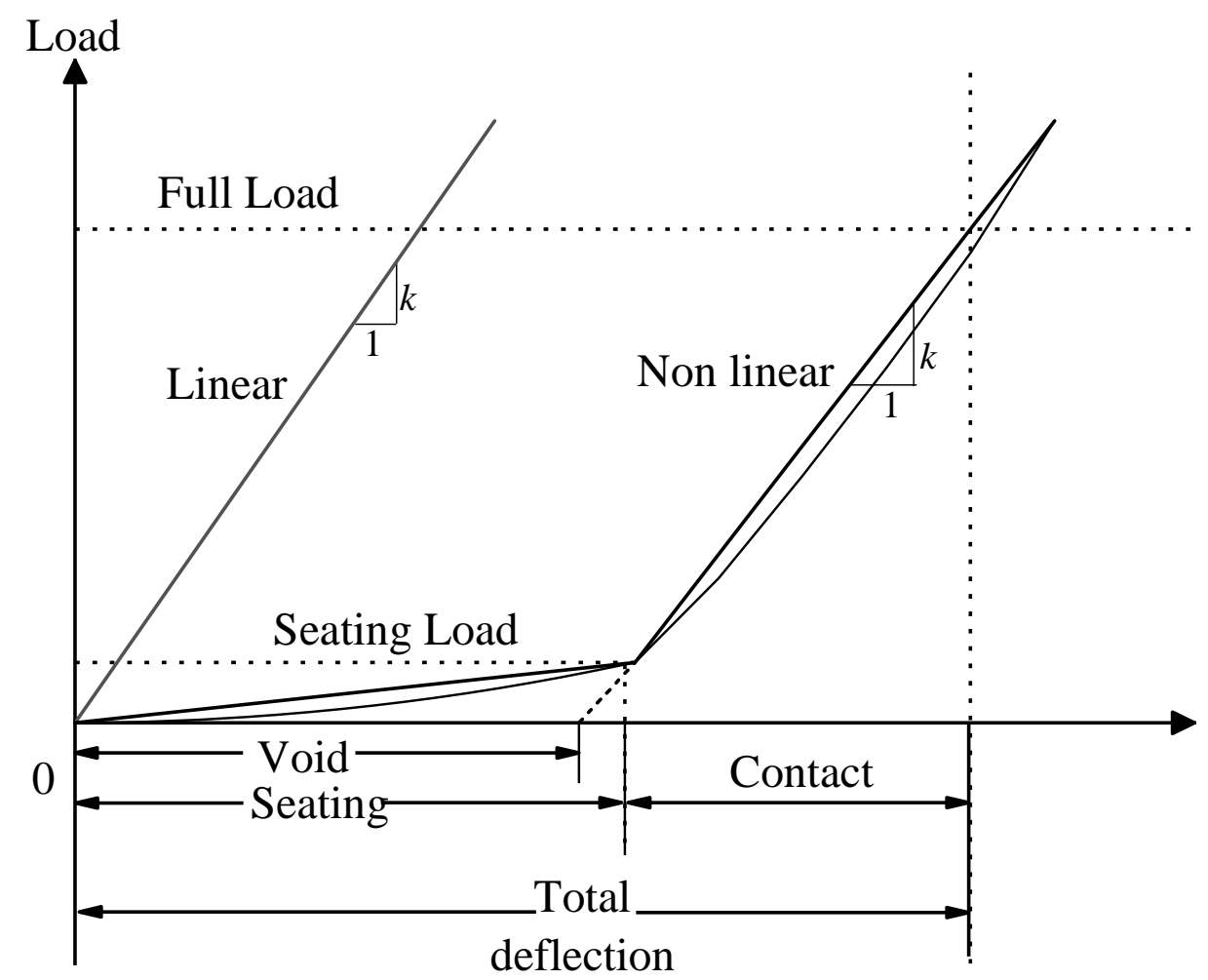

Figure 6: Existence of Void Affecting the Load Carrying behavior of Railroad Tracks (illustration redrawn from Li et al., 2015)

1. Compile the transient responses recorded under the passage of multiple trains on a particular day at a particular location into one dataset;

2. Extract the loads recorded by the strain gauge circuit mounted on top of the instrumented tie, and the corresponding layer transient deformations recorded by the top-most LVDT (mounted inside the instrumented tie);

3. Plot the recorded loads vs. the corresponding deflections measured by the top LVDT;

4. Gradually increase the threshold load level assumed to establish full-contact between the tie and the underlying ballast layer until a clear trend for the load-deflection behavior of the ballast layer is observed;

5. Once a clear inclined portion for the load-deflection curve is obtained, extract the five smallest transient deformation values, and calculate the tie-gap as the mean of those five values.

The PLT approach was used to estimate the tie gaps at the tie-ballast interface for both Madison and Upland Street bridge approaches (listed in Table 3). As seen from the table, the magnitudes keep changing with time. One important thing to note is that the gap at the near bridge location was consistently higher than the open track location except for the August 2012 measurement for Madison Street bridge. Modulus values of individual substructure layers calculated after eliminating the tie-gaps from the peak transient deformations are listed in Table 4. A comparison of the modulus values listed in Table 2 and Table 4, it is noted that the 
backcalculated modulus values for the ballast layer increase significantly after the gap magnitudes have been deducted from the peak transient deformations, which were recorded by the top-most LVDT. Note that new modulus values for the ballast and subballast layers (after consideration of the tie gaps) agree with values commonly reported in the literature.

Table 3: Gap Quantification at the Tie-Ballast Interface using the Progressive Load Threshold Approach: Madison Street Bridge Approach

\begin{tabular}{|c|c|c|c|c|}
\hline \multirow{2}{*}{} & \multicolumn{2}{|c|}{ Madison Street Bridge } & \multicolumn{2}{c|}{ Upland Street Bridge } \\
\cline { 2 - 5 } & $\begin{array}{c}\text { Near-Bridge } \\
\text { Location }\end{array}$ & $\begin{array}{c}\text { Open-Track } \\
\text { Location }\end{array}$ & $\begin{array}{c}\text { Near-Bridge } \\
\text { Location }\end{array}$ & $\begin{array}{c}\text { Open-Track } \\
\text { Location }\end{array}$ \\
\hline Gap $(\mathrm{mm})$ & Gap $(\mathrm{mm})$ & Gap $(\mathrm{mm})$ & Gap $(\mathrm{mm})$ \\
\hline Nov.2012 2012 & 0.55 & 1.12 & 1.53 & 0.34 \\
\hline Jan. 2013 & 0.92 & 0.59 & 1.98 & 0.24 \\
\hline Jun. 2013 & 1.37 & 0.61 & 1.32 & 0.28 \\
\hline
\end{tabular}

Table 4: Track Substructure Layer Modulus Values for (a) Madison Street and (b) Upland Street Locations Estimated using GEOTRACK - After Correcting for Tie-Gaps

(a)

\begin{tabular}{|l|l|l|l|l|l|l|l|l|l|}
\hline \multicolumn{3}{|c|}{ Madison-Near Bridge Location (MPa) } & \multicolumn{3}{c|}{ Madison-Open-Track Location (MPa) } \\
\hline Layer & $\begin{array}{l}\text { Aug } \\
\mathbf{2 0 1 2}\end{array}$ & $\begin{array}{l}\text { Nov } \\
\mathbf{2 0 1 2}\end{array}$ & $\begin{array}{l}\text { Jan } \\
\mathbf{2 0 1 3}\end{array}$ & $\begin{array}{l}\text { June } \\
\mathbf{2 0 1 3}\end{array}$ & Layer & $\begin{array}{l}\text { Aug } \\
\mathbf{2 0 1 2}\end{array}$ & $\begin{array}{l}\text { Nov } \\
\mathbf{2 0 1 2}\end{array}$ & $\begin{array}{l}\text { Jan } \\
\mathbf{2 0 1 3}\end{array}$ & $\begin{array}{l}\text { June } \\
\mathbf{2 0 1 3}\end{array}$ \\
\hline Ballast & 70 & 94 & 102 & $\mathbf{7 8}$ & Ballast & 32 & 155 & 96 & 105 \\
\hline $\begin{array}{l}\text { Fouled } \\
\text { Ballast }\end{array}$ & 70 & 94 & 102 & $\mathbf{7 8}$ & $\begin{array}{l}\text { Fouled Ballast + } \\
\text { Hard Pan }\end{array}$ & 56 & 80 & 80 & 60 \\
\hline Hard Pan & 37 & 51 & 57 & 40 & Silty Clay & 35 & 39 & 41 & 34 \\
\hline $\begin{array}{l}\text { Grey Sandy } \\
\text { Loam + } \\
\text { Cinder }\end{array}$ & 41 & 60 & 42 & 39 & Silty Clay & 35 & 39 & 41 & 34 \\
\hline $\begin{array}{l}\text { Brown Silty } \\
\text { Clay }\end{array}$ & 36 & 36 & 38 & 35 & Fat Clay & 54 & 50 & 54 & 49 \\
\hline
\end{tabular}


(b)

\begin{tabular}{|l|c|c|c|c|l|c|c|c|c|}
\hline \multicolumn{4}{|c|}{ Upland-Near Bridge Location (MPa) } & \multicolumn{4}{|c|}{ Upland-Open-Track Location (MPa) } \\
\hline Layer & $\begin{array}{l}\text { Aug } \\
\mathbf{2 0 1 2}\end{array}$ & $\begin{array}{l}\text { Nov } \\
\mathbf{2 0 1 2}\end{array}$ & $\begin{array}{l}\text { Jan } \\
\mathbf{2 0 1 3}\end{array}$ & $\begin{array}{l}\text { June } \\
\mathbf{2 0 1 3}\end{array}$ & Layer & $\begin{array}{l}\text { Aug } \\
\mathbf{2 0 1 2}\end{array}$ & $\begin{array}{l}\text { Nov } \\
\mathbf{2 0 1 2}\end{array}$ & $\begin{array}{l}\text { Jan } \\
\mathbf{2 0 1 3}\end{array}$ & $\begin{array}{l}\text { June } \\
\mathbf{2 0 1 3}\end{array}$ \\
\hline Ballast & 153 & 40 & 100 & 34 & Ballast & 184 & 205 & 180 & 230 \\
\hline $\begin{array}{l}\text { Fouled } \\
\text { Ballast }\end{array}$ & 80 & 111 & 87 & 77 & $\begin{array}{l}\text { Fouled } \\
\text { Ballast }\end{array}$ & 19 & 57 & 60 & 54 \\
\hline $\begin{array}{l}\text { Sandy Loam } \\
+ \text { Thin Sand } \\
\text { Layer }\end{array}$ & 33 & 43 & 39 & 42 & $\begin{array}{l}\text { Sandy } \\
\text { Loam }\end{array}$ & 31 & 30 & 31 & 31 \\
\cline { 2 - 11 } & 33 & 43 & 39 & 42 & $\begin{array}{l}\text { Clayey } \\
\text { Silt }\end{array}$ & 37 & 33 & 31 & 32 \\
\hline Sandy Loam & 123 & 110 & 118 & 111 & $\begin{array}{l}\text { Sandy } \\
\text { Loam }\end{array}$ & 70 & 70 & 64 & 70 \\
\hline
\end{tabular}

After quantification of the gaps at the tie-ballast interface, the next task involved re-calculating the transient deformations of the ballast layer by subtracting the tie gap values from the total deformations recorded by the top-most LVDT in the MDD system. This is particularly important for accurate representation and interpretation of the ballast layer conditions at the instrumented locations. Accordingly, Figure 7 shows the ballast layer transient responses calculated for the Madison and Upland Street bridge approaches, respectively, through subtraction of the calculated tie gaps from the LVDT 1 measured responses. It is interesting to note that all the instrumented locations except for the Madison Street open-track location exhibited relatively consistent ballast transient deformation magnitudes under train loading. As all the data points presented in the figure correspond to the measurements taken during the passage of Acela express trains, it is safe to assume that the load magnitudes remain relatively constant across time. This observation can be used to conclude that most deterioration in the track geometry at the instrumented locations can be linked to loss of support underneath ties, and does not necessarily indicate deterioration of the ballast layer per se. From Figure 7 it is also evident that the magnitude of the gap at the tie-ballast interface increase with time, particularly for the nearbridge locations (exception: a slight decrease in the tie gap is observed for the Upland Street NBL from November 2012 to January 2013). 

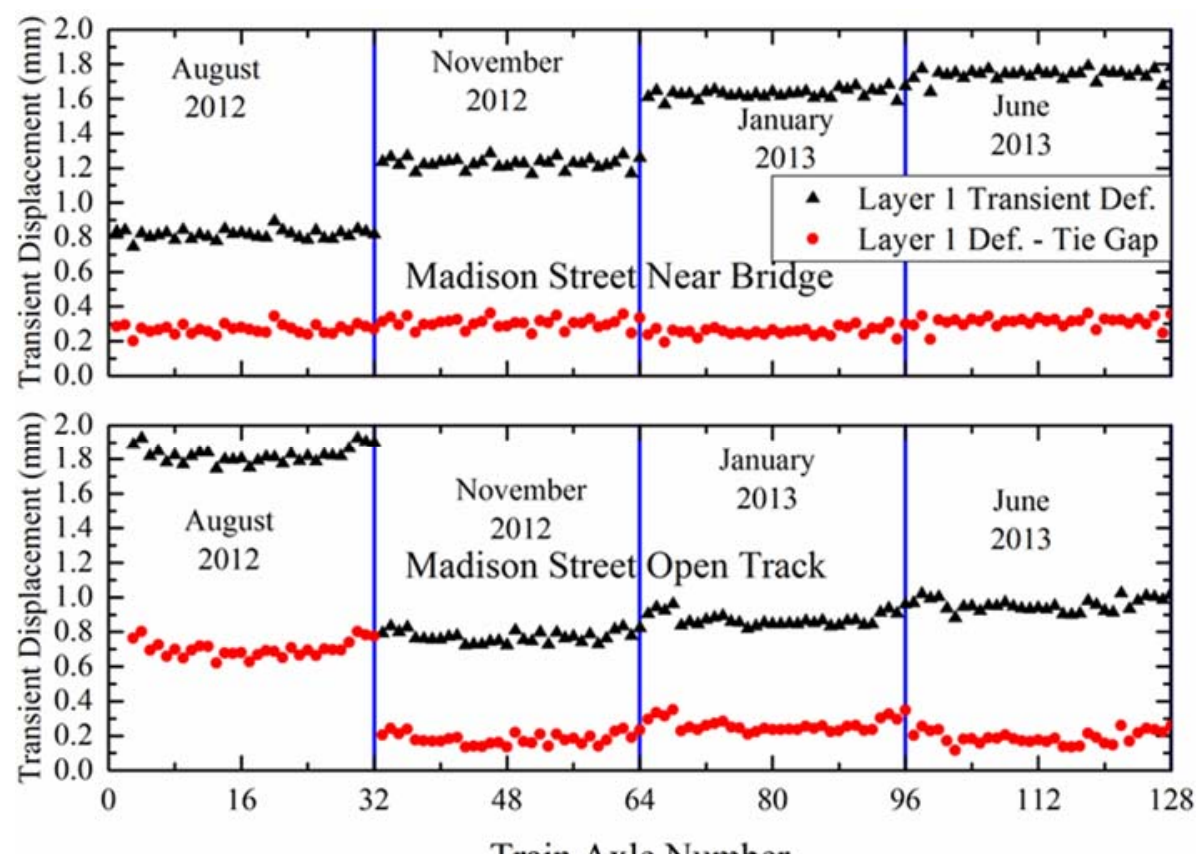

Train Axle Number

(a)
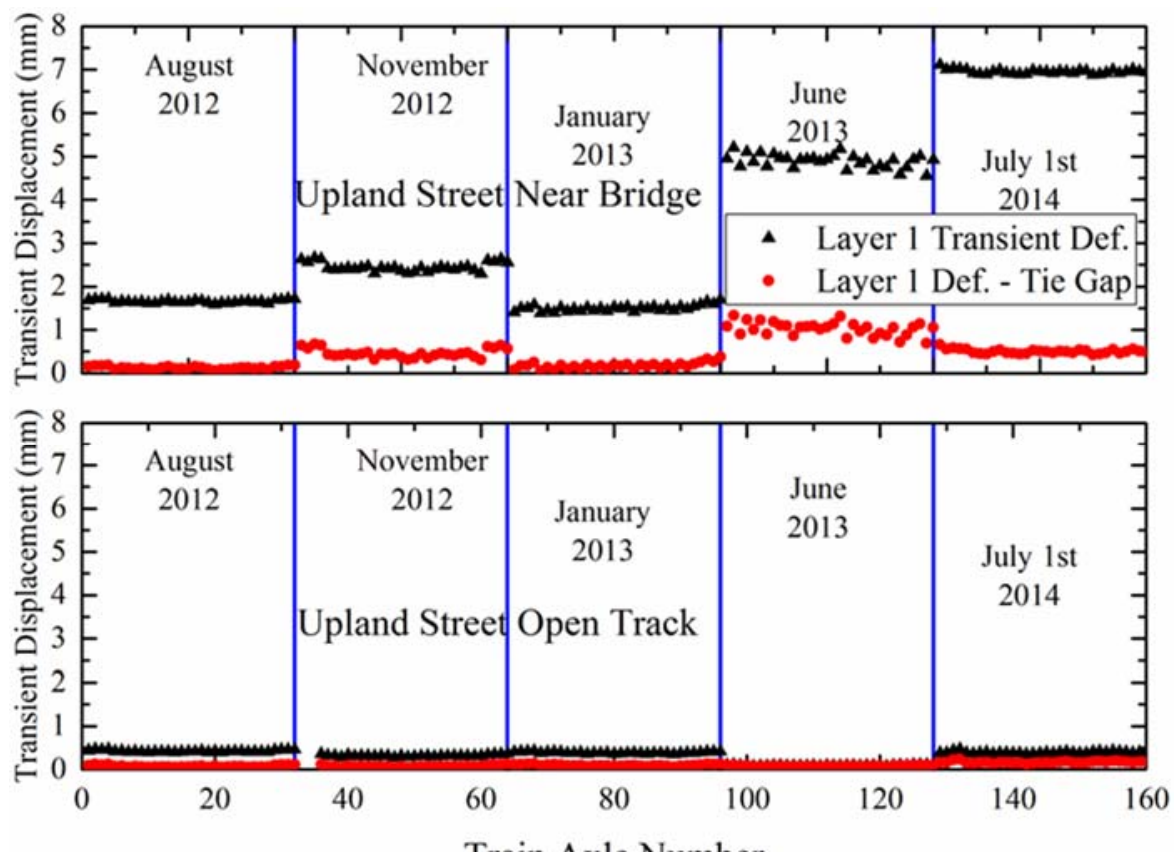

Train Axle Number

(b)

Figure 7: Transient Deformations of the Ballast Layer Calculated through Subtraction of Tie Gaps from LVDT 1 Measurements: (a) Madison Street; and (b) Upland Street

\section{DEVELOPMENT OF A 3-D FEM MODEL FOR SUBSTRUCTURE ANALYSIS}

Numerical models are useful tools for understanding railroad track behavior under different loading and track configurations. Although layered elastic analysis programs such as GEOTRACK can be effectively used to gain basic understanding of track behavior, they are 
limited in terms of their applicability as elastic layered theory is based on certain simplifying assumptions. To facilitate an in-depth understanding of track substructure behavior under varying conditions, advanced numerical modeling approaches such as Finite Element (FE) modeling can be particularly useful. In this study, GEOTRACK was utilized to obtain track modulus values that were subsequently used in a newly developed 3-D FE track model. The commercially available FEM modeling package ABAQUS ${ }^{\circledR}$ was used for this purpose. The following sections present details of this model development efforts. Note that the 3-D FE model is based on the track substructure layer modulus values established using GEOTRACK. Since GEOTRACK is a layered-elastic analysis program and uses linear elastic material formulation to represent granular ballast, subballast if any, and subgrade, similar linear elastic material formulations were used in the FE model. The primary effort was concentrated around selecting certain model parameters such as the mesh size and the geometry, type of elements used, boundary conditions, and loading details to ensure adequate replication of the field-observed trends. Note that while the instrumentation used in this study resided in track transition locations, the modelling effort primarily focused on studying track substructure behavior at open-track locations (i.e. the bridge abutment was not included in the model). Several researchers have published results from numerical modeling of track transitions (Arlaud et al. 2016; Fortunato et al. 2013; Li and Bian 2016; Sañudo et al. 2016; Wang and Markine 2018).

\subsection{Material Formulation}

Several studies (Ferreira and Teixeira 2012; Kabo 2006; Leshchinsky and Ling 2013; Yu et al. 2011) made use of elasto-plastic material formulations like Drucker-Prager method to model the behaviour of ballast and/or subgrade layers. While Lei (2001) used the K- $\theta$ nonlinear elastic modulus model, Banimahd et al. (2013) used the Uzan $(1985,1992)$ nonlinear elastic material model to represent ballast and subgrade layers. Yu et al. (2011), and Leshchinsky and Ling (2013) on the other hand, used linear elastic material formulations only for subgrade. Finally, Real et al. (2016) used linear elastic material formulation for granular layers with an additional damping factor obtained from accelerometers in the field. Note that the instrumentation effort during the current study focused on the measurement of wheel loads and the displacements of individual track substructure layers. No measurement of the stress distribution within the ballast layer was performed. Moreover, due to site access related restrictions, the research team was not able to collect sufficient amounts of ballast samples to be studied in the laboratory for establishing the stress-dependent resilient modulus characteristics. Therefore, the track substructure layers have been assumed to be linear-elastic with constant modulus properties for the 3-D FE modeling purposes.

\subsection{Model Geometry}

Kim et al. (2009) investigated finite element mesh size and geometry that could be adequately used for a 3-D multi-layered model to match semi-infinite axisymmetric elastic layered analysis results for pavement foundations. They concluded that the size of the mesh in an FE model had to be at least 20 times the circular wheel loading radius in the horizontal direction and 140 times the wheel loading radius in the vertical direction in order to overcome infinite boundary assumptions inherent to the elastic layered theory. Modeling efforts in the current study utilized 
the findings mentioned above to define the mesh size and model geometries. Details concerning the model geometry are given below.

GEOTRACK utilizes 11-ties to calculate stresses and deformations under static loading. A space of 11-ties was considered in the FEM model to match a similar geometry as GEOTRACK. The distance between the centers of the first and the eleventh tie was approximately $6.1 \mathrm{~m}$ (based on the standard center-to-center spacing of $61 \mathrm{~cm}$ ). The base width and the length of each tie were $0.274 \mathrm{~m}$ and $2.590 \mathrm{~m}$, respectively. Considering the symmetry of the track structure about the center of the tie, only half of the track was modeled to reduce the computational efforts. Accordingly, only half the length of the tie $(1295.4 \mathrm{~mm})$ was modeled. The base of each half-tie was divided into 5 equal segments to replicate the approach adopted in GEOTRACK. Considering an eleven-tie segment for analysis, the total dimension of the analysis segment was $6.096 \mathrm{~m}$ by $1.295 \mathrm{~m}$. To ensure sufficient distance between the analysis segment and the model boundaries, the model dimension along the track longitudinal directions (both from the first and eleventh ties) were extended by $6.096 \mathrm{~m}$. Similarly, the model dimension along the track transverse direction was extended by around $6.3 \mathrm{~m}$. This dimensioning ensured lateral model boundaries to be at a distance greater than the loading radius, which is assumed to be half of one side of one of five rectangular tie segments. The total depth of the substructure (comprising five layers) was $2.515 \mathrm{~m}$ (measured from the top of the MDD anchor to ballast surface). The model was extended by an additional depth of $17.78 \mathrm{~m}$ to ensure sufficient distance between the top of the anchor, and the bottom of the model. Roller boundary conditions and half-track symmetry boundary conditions were used in the model as appropriate. A schematic of the track model created in ABAQUS is shown in Figure 8.

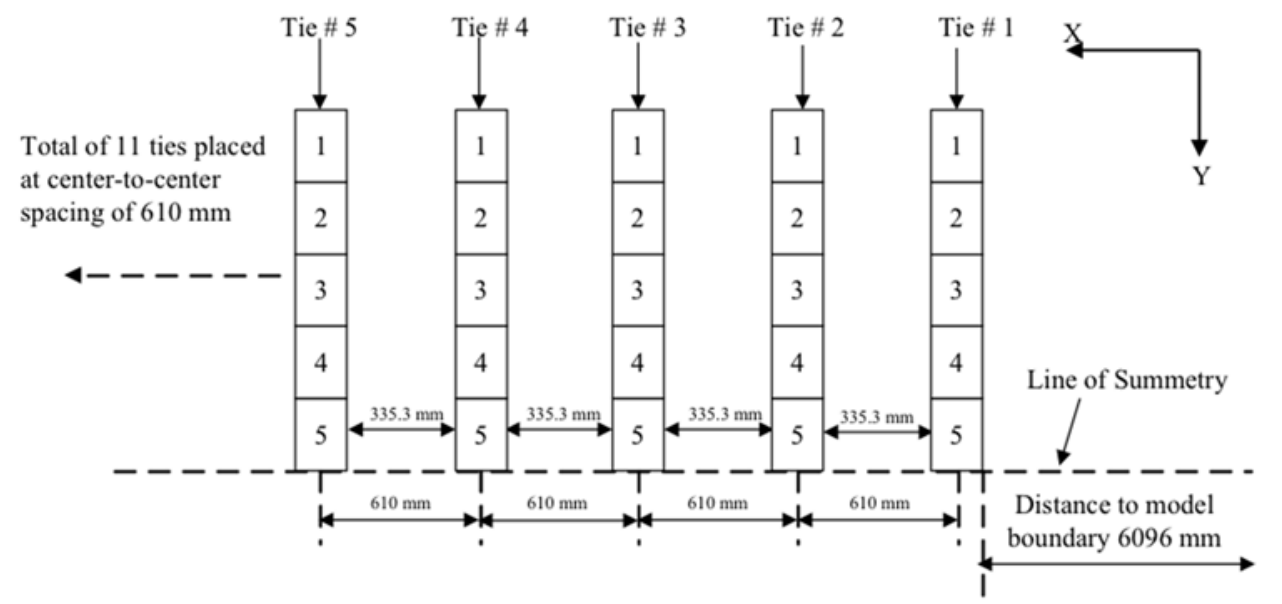

Figure 8: Schematic of the Half-Track Geometry Replicated in the FE Model

\subsection{Mesh Generation}

Two types of isoparametric finite elements used in this study were C3D8 and C3D20, which are available in the standard ABAQUS libraries (ABAQUS 2016).C3D8 is an 8-noded 3-D brick element while C3D20 is a 20-noded brick element. Two mesh scales, coarse and fine were adopted in this study. The coarse-scale mesh contained approximately 50,000 elements, while 
the fine-scale mesh comprised approximately 200,000 elements. Initial results of four meshing type fine and coarse scales with C3D8 and C3D20 elements were considered. Table 5 presents the percent deformation differences between the GEOTRACK and the FEM model for different meshing types. Note that layers 3 and 4 were combined (see Table 5) and treated as one layer during this analysis to accommodate some output formatting issues in GEOTRACK.

Table 5: Predicted Layer Deformations Compared for Different Meshing and Elements

\begin{tabular}{|l|c|c|c|c|}
\hline & $\begin{array}{c}\text { 50400 C3D8 } \\
\text { \% Difference } \\
\text { (GEOTRACK) }\end{array}$ & $\begin{array}{c}\text { 50400 C3D20 } \\
\text { \% Difference } \\
\text { (GEOTRACK) }\end{array}$ & $\begin{array}{c}\text { 204600 C3D8 } \\
\text { \% Difference } \\
\text { (GEOTRACK) }\end{array}$ & $\begin{array}{c}\text { 204600 C3D20 } \\
\text { \% Difference } \\
\text { (GEOTRACK) }\end{array}$ \\
\hline Layer 1 & -8.932 & 0.695 & 0.216 & 0.720 \\
\hline Layer 2 & 1.510 & 0.071 & 0.647 & 0.018 \\
\hline Layer 3+4 & -0.068 & -0.622 & -0.267 & -0.625 \\
\hline Layer 5 & -0.541 & -0.825 & -0.599 & -0.825 \\
\hline
\end{tabular}

The initial results comparison indicated no significant differences between fine and coarse scale meshing when C3D20 elements were used. Therefore, for better computational efficiency with shorter run times, coarse meshing (50,400 elements) with C3D20 elements was selected in this study.

Individual track substructure layer transient displacements predicted using the newly developed 3-D FE model were compared against the field measured and GEOTRACK-predicted values (see Figure 9). As shown in the figure, the results display negligible differences that are likely caused by slight differences in the loading configurations. Note that the newly developed 3-D FE model successfully predicted the peak transient displacements for the individual track substructure layers. It is important to note that the current modeling effort did not distinguish between Near-Bridge and Open-Track locations (NBL and OTL) as far as proximity to the bridge abutment is concerned. In other words, the two models were identical to each other in terms of geometry and boundary conditions except for the layer configuration and modulus properties obtained from the field drilling and MDD instrumentation effort, and the GEOTRACK backcalculation effort, respectively. At this stage, the validated model can further be modified to analyze scenarios that cannot be otherwise analyzed using layered-elastic analysis programs such as GEOTRACK. One such example is analyzing track response under moving load applications. 

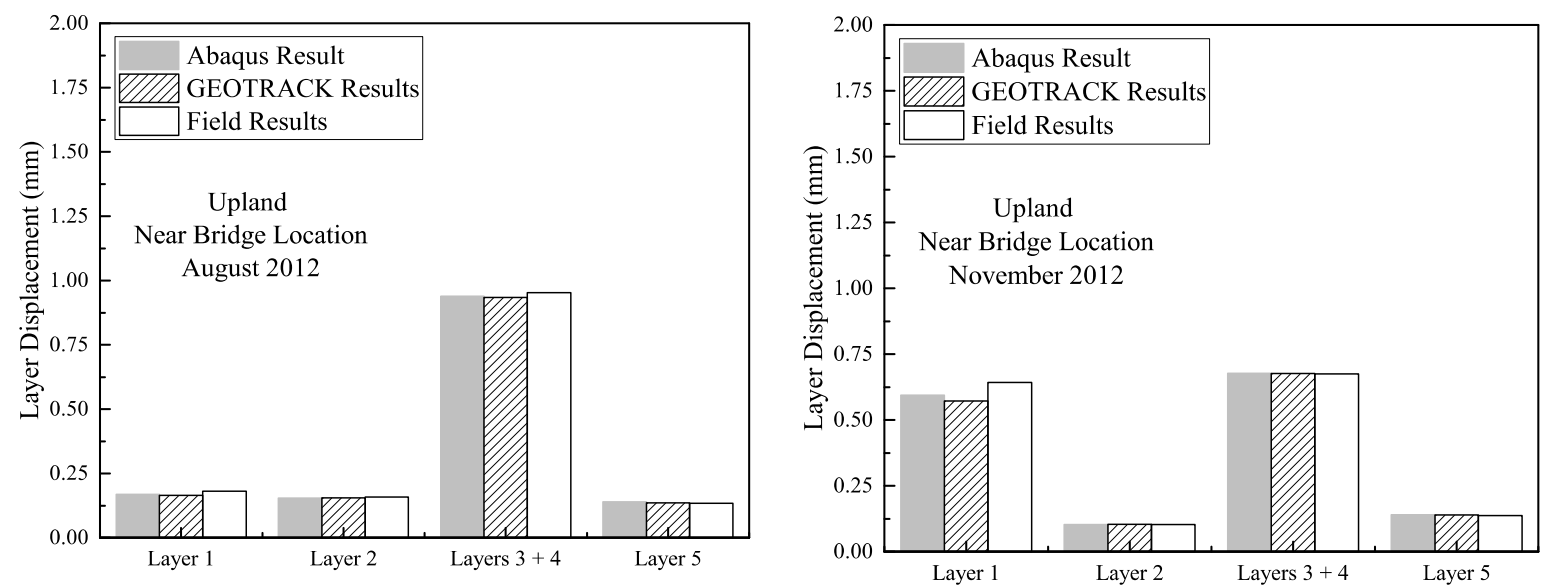

(a) Upland Street NBL-Aug. 2012

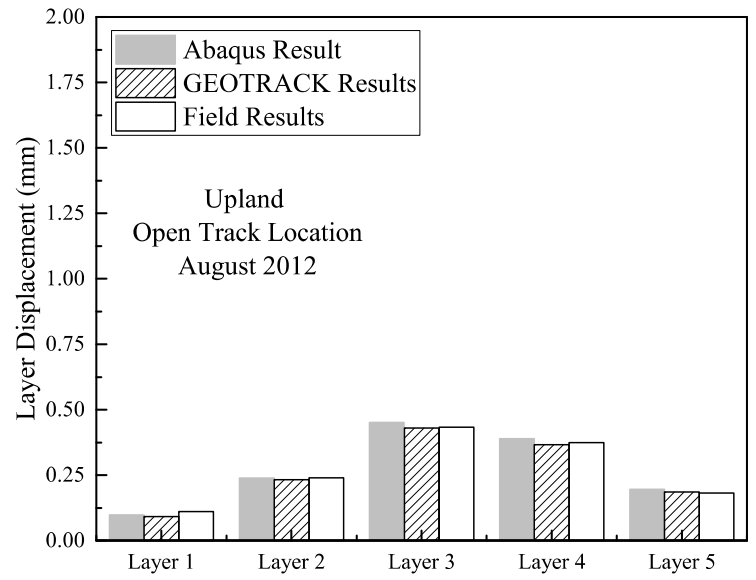

(b) Upland Street NBL-Nov. 2012

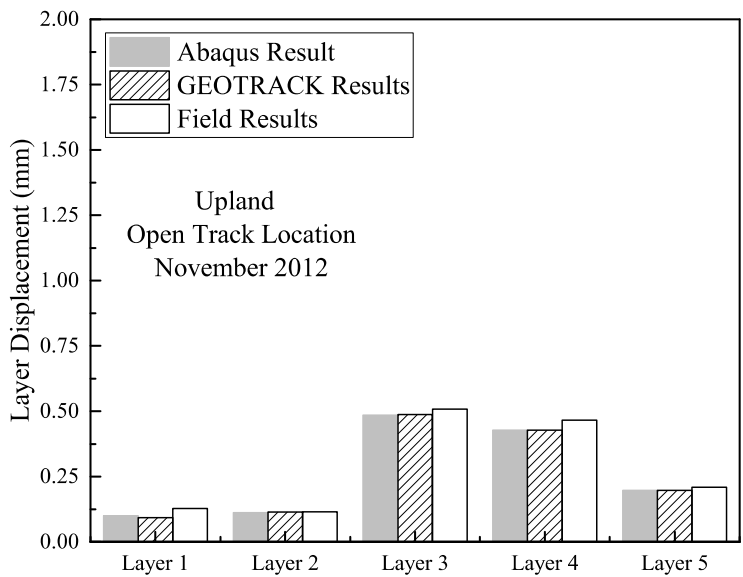

(c) Upland Street OTL-Aug. 2012

(d) Upland Street OTL-Nov. 2012

Figure 9: Comparing Transient Deformations for Individual Track Substructure Layers Predicted by the 3-D FE Model with Field-Measured and GEOTRACK-Predicted Values

\section{ANALYSIS OF TRACK SUBSTRUCTURE RESPONSE UNDER MOVING WHEEL LOADS}

The results presented in the previous section were limited to concentrated static loads corresponding to loads at a given instant of time extracted from the field-measured load time histories. In other words, the movement of the load on the rails was not considered. The next step in this effort involved modifying the newly created 3-D FE model by incorporating moving wheel loads.

Note that the moving load simulation in this study primarily focused on changing the position of the load with time, and did not consider inertia of the track structure components, which would have represented a 'truly dynamic' analysis case. For vehicle speeds below the critical track velocity and assuming minimal dynamic railcar/rail bed interaction, static and dynamic track behavior cases are comparable. As a result, a static FE analysis can, therefore, provide 
reasonably accurate results (Feng 2011; Kouroussis et al. 2015a). Accordingly, to achieve a quasi-static moving wheel load, multiple concentrated point loads were applied to rail nodes in the 3-D FE model. These loads corresponded to the first and last axles/wheels of the last bogie of an ACELA express train. Individual loads were activated in a certain order during the simulation to simulate the movement of the wheels on the rail. This approach can be explained by the discussions presented below.

The 3D FEM model presented in the previous section considered segmentation of the tie loads according to the assumptions made in GEOTRACK analyses. Since the new 3-D FE model would include the actual concrete tie geometry and the associated contact areas for loading, the center of rail was aligned with element boundaries in meshing so that accurate layer displacement results could be predicted. Standard rail gauge used in North America and most regions in the world is $1435.1 \mathrm{~mm}$. This gauge value indicates the distance between inner edges of the surface of rail heads. The distance between the center of rail would then vary with the width of the rail head. The standard 136-lb/yard rail has a head width of approximately $74.613 \mathrm{~mm}$. Therefore, the distance between rail centers is around $1510 \mathrm{~mm}$. This value has also been used in GEOTRACK. Therefore, the distance between the center of tie (half symmetry plane) and rail center is around $755 \mathrm{~mm}$. The rail was modeled using a rectangular geometry with a length that spans 11 ties. Three-noded quadratic beam elements (B32 in ABAQUS libraries; ABAQUS, 2016) were used to mesh the rail. Relevant dimensions and material properties for the half concrete tie as well as the rail have been listed in Table 6 . The rectangular dimensions of the rail had a similar moment of inertia value to the $136 \mathrm{lb} / \mathrm{yard}$ (67.46 $\mathrm{kg} / \mathrm{m}$ ) rail observed in the field. Full bonding (no separation) was assumed between the rail and the ties, as well as at tie-ballast interface.

\section{Table 6: Relevant Dimensions and Material Properties of Half Concrete Tie and Rail used during the Modeling Effort}

\begin{tabular}{|l|l|l|}
\hline & Half Concrete Tie & Rail \\
\hline Young's Modulus $(\mathrm{MPa})$ & $2.07 \mathrm{E}+04$ & $2.07 \mathrm{E}+05$ \\
\hline Poisson's Ratio & 0.15 & 0.25 \\
\hline Length $(\mathrm{mm})$ & 1295.4 & Span 11 Ties \\
\hline Base Width $(\mathrm{mm})$ & 274.32 & 152.4 \\
\hline Top Width $(\mathrm{mm})$ & 228.6 & 152.4 \\
\hline Height $(\mathrm{mm})$ & 177.8 & 177.8 \\
\hline
\end{tabular}

In the previous model an 11-tie loading assembly was used to primarily accommodate GEOTRACK geometry and analysis requirements. However, eleven ties were simply not enough to simulate moving wheel loads. For example, if one considers the center tie (the $6^{\text {th }}$ tie in an 11-tie system) as tie number 0, when the first axle/wheel of an ACELA locomotive bogie is placed on top of this tie, the second axle/wheel must be placed $2844.8 \mathrm{~mm}$ behind the first one, which corresponds to a distance more than $4 \frac{1}{2}$ tie spacing length. Therefore, the rear axle/wheel load is placed between the $10^{\text {th }}$ and $11^{\text {th }}$ ties. For the sake of argument, these ties would be called Tie No. (-4) and Tie No. (-5), respectively. If the first axle/wheel load is placed 
on Tie No. (-1), which is right behind the center tie, rear axle/wheel load must now be placed between Tie No. (5) and Tie No. (6). Obviously, for an 11-tie system, Tie No. (6) does not exist, and accordingly, even a simple one tie approach to center tie cannot not be achieved. To remedy this limitation, 10 more ties were added to the FEM model, five ties behind Tie No. (-5), and five ties in front of Tie No. (5). In what follows, the geometry was re-sectioned accordingly and the rail length was increased in the model. Figure 10 displays a 3D view of the new 3D FEM model now created with 21 ties.

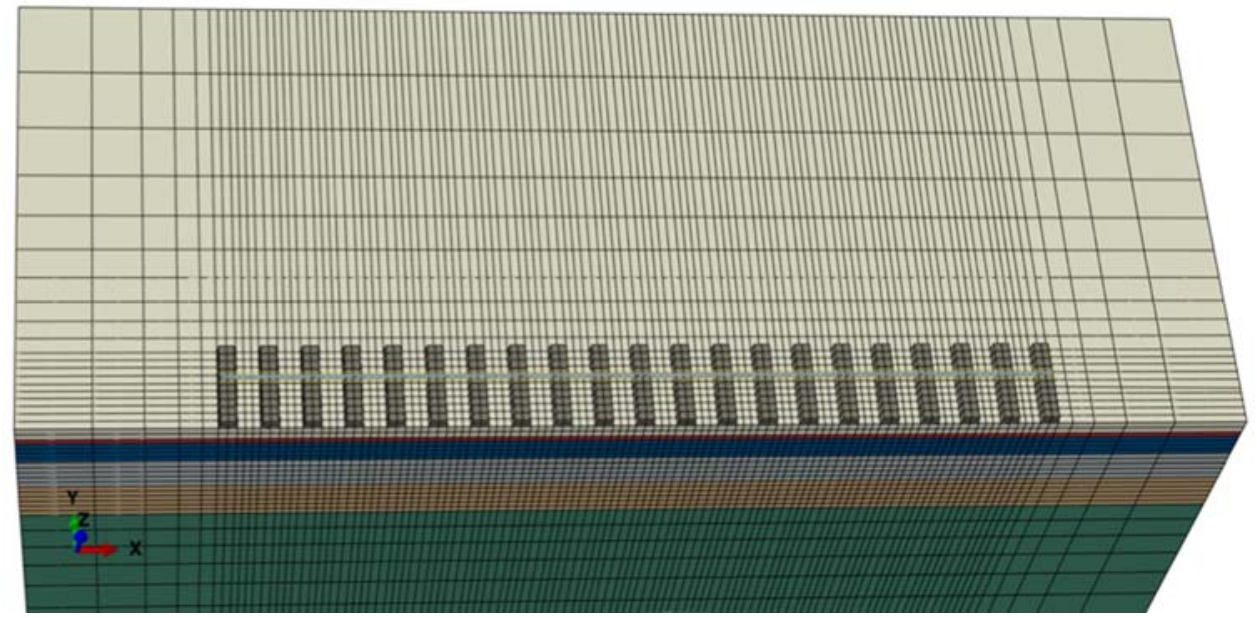

Figure 10: 3-D View of the FEM Model showing Half Ties and Rail Assembly

To achieve a quasi-static moving wheel load, 32 concentrated point loads representing the first and the last axles/wheels of the last bogie of an ACELA train were applied to rail nodes. These loads were activated in a certain order to achieve a quasi-static movement. The center tie in the analysis segment is denoted as Tie No. (0). The two ties adjacent to the central tie denoted as Tie No. (-1) and Tie No. (+1). Similarly, subsequent ties are designated (-2), (-3), (-4), etc. on one side, $(+2),(+3),(+4)$, etc. on the other side. Based on the distance $(2844.8 \mathrm{~mm})$ between the two rear axles on the locomotive, positions of two wheels along the rail at any instant can be defined by activating two concentrated wheel loads previously assigned to the corresponding rail nodes. Each of these two concentrated loads are named as one load set. All the load sets used in the simulation are listed in Table 7. To be able to analyze deformation under the center tie with the total approach and departure of the locomotive bogie, the initial position of the front axle was located on Tie No. (-5) with rear axle being between the Tie No.s (-9) and (-10). Similarly, in the last load step front and rear axles are located on Tie No. (+10) and between Tie No.s (+5) and (+6). Therefore, a total of 16 load sets are defined. Once the simulation starts, the leading wheel moves gradually towards Tie No. (+10) while rear axle follows at a distance of $\sim 4.6$ tie span (equal to the distance of $2844.8 \mathrm{~mm}$ between the two loads). 


\section{Table 7: Sequence of Concentrated Load Positions used for the Moving Wheel Load}

Simulations

\begin{tabular}{|c|c|c|}
\hline $\begin{array}{l}\text { Load Set } \\
\text { Number }\end{array}$ & $\begin{array}{c}\text { Location of Front Axle / } \\
\text { Wheel Load On Tie } \\
\text { Number }\end{array}$ & $\begin{array}{c}\text { Location of Rear Axle / } \\
\text { Wheel Load between Tie } \\
\text { Numbers }\end{array}$ \\
\hline 1 & $(-5)$ & $(-9)$ and $(-10)$ \\
\hline 2 & $(-4)$ & $(-8)$ and $(-9)$ \\
\hline 3 & $(-3)$ & $(-7)$ and $(-8)$ \\
\hline 4 & $(-2)$ & $(-6)$ and $(-7)$ \\
\hline 5 & $(-1)$ & $(-5)$ and $(-6)$ \\
\hline 6 & (0) & $(-4)$ and $(-5)$ \\
\hline 7 & (1) & $(-3)$ and $(-4)$ \\
\hline 8 & (2) & $(-2)$ and $(-3)$ \\
\hline 9 & (3) & $(-1)$ and $(-2)$ \\
\hline 10 & (4) & $(0)$ and $(-1)$ \\
\hline 11 & (5) & (1) and (0) \\
\hline 12 & (6) & (2) and (1) \\
\hline 13 & (7) & (3) and (2) \\
\hline 14 & (8) & (4) and (3) \\
\hline 15 & (9) & (5) and (4) \\
\hline 16 & (10) & (6) and (5) \\
\hline
\end{tabular}

As already mentioned, the current modeling effort did not consider time-dependent properties of the layers, such as inertia and damping. Accordingly, the speed of movement of the concentrated wheel loads does not have any effect on the predicted response. Similarly, since material properties used were all linear elastic, the time step used does not affect any dynamic inertial effect in the model. Therefore, the simulation can be replicated by any other quasi-static approach with varying time step amounts. A tabular amplification approach was used to activate the loads. For instance, at 0+t (time step)-second in simulation time, load set one in Table 7 was assigned an amplitude of 1 while the other load sets were assigned amplitudes of 0 . Similarly, during next time step (simulation time $=0+2$ t seconds), load set two was assigned an amplitude of 1 while the rest were assigned an amplitude of 0 . This enabled the location and relocation of the concentrated wheel loads relative to center tie.

To illustrate the capabilities of this moving load simulation, field measurements made in Upland Street open track location in August 2012 were compared with the modeling results. Based on the field-measurements, a wheel load magnitude of $124.8 \mathrm{kN}$ was assigned to both concentrated loads comprising a load set (corresponding to the two axles on the trailing locomotive of an ACELA express train). Note that due to symmetric conditions, only one side of an axle was applied on the top of the rail during this modeling effort. To facilitate comparison of FEM predictions with the field-measured values, the load time histories collected through the 
strain gauges were trimmed to a 0.2-second window representing the approach and departure of the last two axles with respect to the instrumented tie [see

Figure 11 (a)]. Predictions from the 3-D FE model are presented in Figure 11 (b).

Both Figures 11(a) and 11(b) show the change in vertical displacement of the center tie (instrumented tie; Tie No. (0) in the FE model) when the leading axle load is located at different points along the rail. To facilitate direct comparison, the two figures contain a secondary horizontal axis. In Figure 11 (a), secondary horizontal axis shows estimated location of the leading axle load (based on the train speed), while in Figure 11 (b), secondary axis represents the estimated time in seconds. Note that both secondary horizontal axes are based on a train speed of $177 \mathrm{~km} / \mathrm{h}$, which corresponds to the speed of this particular train estimated in the field.

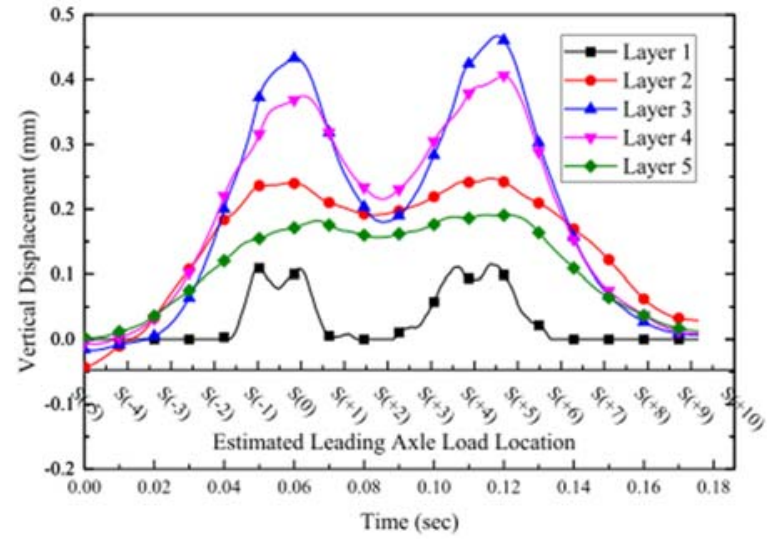

(a) Field MDD Measurement

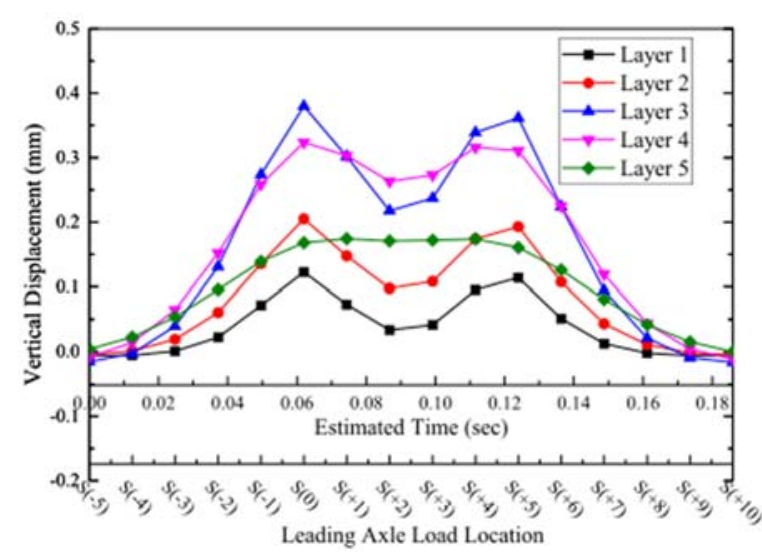

(b) FEM Model Results

\section{Figure 11: Comparison of FEM Model with Field Measurements with Moving Wheel Load for Upland Street Open Track Locations, August 2012}

As already listed in Table 3, a gap approximately $0.34 \mathrm{~mm}$ existed at the tie-ballast interface at the Upland Street OTL in August 2012. To compare the transient deformation measured in the field to those predicted by the 3-D FE model under moving wheel loads, the gap amount of 0.34 $\mathrm{mm}$ was subtracted from the LVDT 1 measurements before plotting them in Figure 11 (a).

Figure 11 (b) shows the predicted transient deformations for all substructure layers indicating similar trends to the field-measured ones. The difference in the shape of the trace for Layer 1 is expected as the field-measured values have been manually reduced by a magnitude of 0.34 $\mathrm{mm}$ to account for the gap at the tie-ballast interface. Nevertheless, it should be noted that both the model-predicted and field-measured traces indicate peak transient displacement values of approximately $0.1 \mathrm{~mm}$. A significant difference is observed between the two traces for Layer 2 . While the model-predicted results show a drastic reduction in Layer 2 displacement between the two peak values, this drop is less pronounced in the field. It should also be highlighted that the 
model, in its current form, cannot reflect changes in transient displacements due to dynamic nature that could be observed in the field. Therefore, slight differences in results are to be expected.

Another important observation made from comparing the two traces presented in Figure 11 concerns the interaction of the wheel load effects for layers in greater depths in the substructure. Although distinct peaks in the displacement time history corresponding to individual peaks in the load time history are observed for shallow layers, these peaks get smoothened in the displacement time histories for layers that are relatively deep in the track substructure. This phenomenon, referred to as 'multiple wheel load interaction,' was studied in the case multiple wheel aircraft gear configurations by Kim and Tutumluer (2008), and is clearly evident for the Layer 5 time histories shown in

Figure 11 . Note that this can be primarily attributed to the intersecting load dissipation cones as one moves deeper into the substructure.

\section{SUMMARY AND CONCLUSIONS}

This manuscript presented findings from a recent research project that utilized field instrumentation and numerical modeling to investigate different factors contributing to the differential movement problem at track transitions such as bridge approaches. The overall objective of the manuscript was to highlight how field instrumentation data can be used along with analytical and numerical modeling approaches to gain an in-depth understanding of track substructure behavior. Track response data collected using strain gauges and Multi-Depth Deflectometers (MDDs) were used to iteratively backcalculate modulus values for individual track substructure layers. A new approach, referred to as the Progressive Load Threshold (PLT) was developed to identify and determine any gaps at the tie-ballast interface. Track substructure layer modulus values estimated after accounting for gaps underneath the ties at the tie-ballast interface were used as inputs into the newly developed 3-D finite element analysis model. Once validated, the model was further advanced to incorporate the moving wheel loads in an effort to better replicate the field-measured results. Results obtained from the moving wheel load simulation demonstrated closer matches to the field instrumentation results. Further improvements planned to be implemented in the model include: (1) extending the analysis domain horizontally to include bridge abutment to adequately model the effect of track transitions; (2) modifying the behavior at the tie-ballast interface to allow for separation due to upward bending of the rails; (3) implementing User Material Subroutines (UMATs) to adequately capture the stress-dependent modulus behaviour of geomaterials in the track substructure; and (4) incorporate inertial properties of track substructure layers to investigate their true dynamic response under loading.

\section{ACKNOWLEDGEMENTS}

Research findings described in this paper were made possible through the Federal Railroad Administration (FRA) Broad Agency Announcement funding program for research and 
demonstration projects supporting the development of high-speed and intercity passenger rail service. The authors thank Cameron Stuart and Gary Carr of FRA for the financial support and guidance provided in this project. Sincere thanks go to Jim Hyslip of HyGround Engineering (a Loram company), Ted Sussmann of Volpe Research Center, and Steve Chrismer of ENSCO (previously AMTRAK) for their help and support. The design, manufacturing, and installation of all instrumentation components used in this study were conducted under the guidance of Mike Tomas of Amtrak. Finally, acknowledgments are also due to Marty Perkins and Carl Walker of Amtrak and to Hasan Kazmee, Michael Wnek, and James Pforr of the University of Illinois for their help with the instrumentation activities. The authors also acknowledge the support and contributions of the project co-PI Prof. Timothy D. Stark throughout this research study. The contents of this paper reflect the views of the authors who are responsible for the facts and the accuracy of the data presented herein. This paper does not constitute a standard, specification, or regulation.

\section{CONFLICT OF INTEREST}

The authors declare no potential conflicts of interest with respect to the research, authorship, and/or publication of this article.

\section{REFERENCES}

ABAQUS. 2016. Abaqus 6.14 User's Manual. World Wide Web Address: http://abaqus.software.polimi.it/v6.14/index.html.

Arlaud, E., COSTA D'AGUAR, S., Balmès, E. \& Faussurier, G. 2016. Numerical study of railway track dynamics: Case of a transition zone.

Auersch, L. 2006. Ground vibration due to railway traffic - the calculation of the effects of moving static loads and their experimental verification. Journal of Sound and Vibration, 293, 599-610.

Banimahd, M., Woodward, P., Kennedy, J. \& Medero, G. 2013. Three-dimensional modelling of high speed ballasted railway tracks. Proceedings of the Institution of Civil Engineers-Transport. Thomas Telford Ltd, 113-123.

Boler, H., Mishra, D., Tutumluer, E., Chrismer, S. \& Hyslip, J.P. 2018. Stone blowing as a remedial measure to mitigate differential movement problems at railroad bridge approaches. Proceedings of the Institution of Mechanical Engineers, Part F: Journal of Rail and Rapid Transit, 0954409718778654.

Burmister, D. 1943. Theory of Stress and Displacement in Layered System and Applications to the Design of Airport. Proceedings of Annual Meeting of the Transportation Research Board, Highway Research Board, Washington, DC.

Burmister, D.M. 1945. The general theory of stresses and displacements in layered systems. I. Journal of applied physics, 16, 89-94. 
Burmister, D.M., Palmer, L., Barber, E. \& Middlebrooks, T. 1944. The theory of stress and displacements in layered systems and applications to the design of airport runways. Highway Research Board Proceedings.

Butterworth, S. 1930. On the theory of filter amplifiers. Wireless Engineer, 7, 536-541.

Chang, C.S., Adegoke, C.T. \& Selig, E.T. 1980. Geotrack model for railroad track. Journal of the Geotechnical and Geoenvironmental Engineering, 106, 1201-1218.

Degrande, G. \& Lombaert, G. 2000. High-speed train induced free field vibrations: in situ measurements and numerical modelling. Proceedings of the international workshop Wave, 2941.

Feng, H. 2011. 3D-models of railway track for dynamic analysis, Royal Institute of Technology.

Ferreira, T.M. \& Teixeira, P.F. 2012. Rail track performance with different subballast solutions: Traffic and environmental effects on subgrade service life. Journal of Transportation Engineering, 138, 1541-1550.

Fortunato, E., Paixão, A. \& Calçada, R. 2013. Railway track transition zones: design, construction, monitoring and numerical modelling. International Journal of Railway Technology, 2, 33-58.

Galvin, P., Romero, A. \& Dominguez, J. 2010. Vibrations induced by HST passage on ballast and non-ballast tracks. Soil Dynamics and Earthquake Engineering, 30, 862-873.

Gräbe, P. \& Shaw, F. 2010. Design life prediction of a heavy haul track foundation. Proceedings of the Institution of Mechanical Engineers, Part F: Journal of Rail and Rapid Transit, 224, 337344.

Kabo, E. 2006. A numerical study of the lateral ballast resistance in railway tracks. Proceedings of the Institution of Mechanical Engineers, Part F: Journal of Rail and Rapid Transit, 220, 425433.

Kim, M. \& Tutumluer, E. 2008. Multiple Wheel-Load Interaction in Flexible Pavements. Transportation Research Record: Journal of the Transportation Research Board, 2068, 49-60, doi: 10.3141/2068-06.

Kim, M., Tutumluer, E. \& Kwon, J. 2009. Nonlinear Pavement Foundation Modeling for ThreeDimensional Finite-Element Analysis of Flexible Pavements. International Journal of Geomechanics, 9, 195-208.

Kouroussis, G., Caucheteur, C., Kinet, D., Alexandrou, G., Verlinden, O. \& Moeyaert, V. 2015 a. Review of trackside monitoring solutions: from strain gages to optical fibre sensors. Sensors, 15, 20115-20139. 
Kouroussis, G., Connolly, D.P., Alexandrou, G. \& Vogiatzis, K. 2015b. The effect of railway local irregularities on ground vibration. Transportation Research Part D: Transport and Environment, 39, 17-30.

Kouroussis, G., Connolly, D.P., Forde, M.C. \& Verlinden, O. 2015c. Train speed calculation using ground vibrations. Proceedings of the Institution of Mechanical Engineers, Part F: Journal of Rail and Rapid Transit, 229, 466-483.

Kouroussis, G., Connolly, D.P., Laghrouche, O., Forde, M.C., Woodward, P. \& Verlinden, O. 2015d. Robustness of railway rolling stock speed calculation using ground vibration measurements. MATEC Web of Conferences. EDP Sciences.

Kouroussis, G., Connolly, D.P., Olivier, B., Laghrouche, O. \& Costa, P.A. 2016. Railway cuttings and embankments: Experimental and numerical studies of ground vibration. Science of the Total Environment, 557, 110-122.

Kouroussis, G., Connolly, D.P., Vogiatzis, K. \& Verlinden, O. 2015e. Modelling the environmental effects of railway vibrations from different types of rolling stock: a numerical study. Shock and Vibration, 2015.

Lei, X. 2001. Dynamic analysis of the track structure of a high-speed railway using finite elements. Proceedings of the Institution of Mechanical Engineers, Part F: Journal of Rail and Rapid Transit, 215, 301-309.

Leshchinsky, B. \& Ling, H.I. 2013. Numerical modeling of behavior of railway ballasted structure with geocell confinement. Geotextiles and Geomembranes, 36, 33-43.

Li, D., Hyslip, J., Sussman, T.R. \& Chrismer, S.M. 2015. Railway Geotechnics. CRC Press.

Li, W. \& Bian, X. 2016. Dynamic performance of pile-supported bridge-embankment transition zones under high-speed train moving loads. Procedia engineering, 143, 1059-1067.

Ling, X.-Z., Chen, S.-J., Zhu, Z.-Y., Zhang, F., Wang, L.-N. \& Zou, Z.-Y. 2010. Field monitoring on the train-induced vibration response of track structure in the Beiluhe permafrost region along Qinghai-Tibet railway in China. Cold Regions Science and Technology, 60, 75-83.

Lombaert, G., Degrande, G., Kogut, J. \& François, S. 2006. The experimental validation of a numerical model for the prediction of railway induced vibrations. Journal of Sound and Vibration, 297, 512-535.

Mishra, D., Boler, H., Tutumluer, E. \& Hyslip, J.P. 2016. Effectiveness of Chemical Grouting and Stone Blowing as Remedial Measures to Mitigate Differential Movement at Railroad Track Transitions. 2016 Joint Rail Conference. American Society of Mechanical Engineers, V001T001A030-V001T001A030.

Mishra, D., Qian, Y., Huang, H. \& Tutumluer, E. 2014a. An integrated approach to dynamic analysis of railroad track transitions behavior. Transportation Geotechnics, 1, 188-200. 
Mishra, D., Tutumluer, E., Boler, H., Hyslip, J. \& Sussmann, T. 2014b. Railroad Track Transitions with Multidepth Deflectometers and Strain Gauges. Transportation Research Record: Journal of the Transportation Research Board, 105-114.

Mishra, D., Tutumluer, E., Stark, T.D., Hyslip, J.P., Chrismer, S.M. \& Tomas, M. 2012. Investigation of differential movement at railroad bridge approaches through geotechnical instrumentation. Journal of Zhejiang University SCIENCE A, 13, 814-824.

Namura, A. \& Suzuki, T. 2007. Evaluation of countermeasures against differential settlement at track transitions. Quarterly Report of RTRI, 48, 176-182.

Paixão, A., Alves Ribeiro, C., Pinto, N., Fortunato, E. \& Calçada, R. 2015. On the use of under sleeper pads in transition zones at railway underpasses: experimental field testing. Structure and Infrastructure Engineering, 11, 112-128.

Pinto, N., Ribeiro, C.A., Gabriel, J. \& Calçada, R. 2015. Dynamic monitoring of railway track displacement using an optical system. Proceedings of the Institution of Mechanical Engineers, Part F: Journal of Rail and Rapid Transit, 229, 280-290.

Priest, J., Powrie, W., Yang, L., Grabe, P. \& Clayton, C. 2010. Measurements of transient ground movements below a ballasted railway line. Géotechnique, 60, 667-677.

Real, T., Zamorano, C., Hernández, C., García, J. \& Real, J. 2016. Static and dynamic behavior of transitions between different railway track typologies. KSCE Journal of Civil Engineering, 20, 1356-1364.

Sañudo, R., Dell'Olio, L., Casado, J., Carrascal, I. \& Diego, S. 2016. Track transitions in railways: A review. Construction and Building Materials, 112, 140-157.

Scullion, T., Briggs, R.C. \& Lytton, R.L. 1989. Using the multidepth deflectometer to verify modulus backcalculation procedures. Nondestructive Testing of Pavements and Backcalculation of Moduli. ASTM International.

Selig, E.T. \& Waters, J.M. 1994. Track Geotechnology and Substructure Management. Thomas Telford.

Stewart, H.E. \& Selig, E.T. 1982. Predicted and measured resilient response of track. Journal of the Geotechnical Engineering Division, 108, 1423-1442.

Sussmann, T.R. \& Selig, E.T. 2000. Resilient Modulus Backcalculation Techniques for Track. Performance Confirmation of Constructed Geotechnical Facilities. ASCE, 401-411.

Tutumluer, E., Stark, T.D., Mishra, D. \& Hyslip, J.P. 2012. Investigation and mitigation of differential movement at railway transitions for US high speed passenger rail and joint passenger/freight corridors. 2012 Joint Rail Conference. American Society of Mechanical Engineers, 75-84.

Uzan, J. 1985. Characterization of granular material. Transportation Research Record. 
Uzan, J. 1992. Resilient characterization of pavement materials. International Journal for Numerical and Analytical Methods in Geomechanics, 16, 453-459.

Wang, H. \& Markine, V.L. 2018. Methodology for the comprehensive analysis of railway transition zones. Computers and geotechnics, 99, 64-79.

Yu, H., Jeong, D., Choros, J. \& Sussmann, T. 2011. Finite element modeling of prestressed concrete crossties with ballast and subgrade support. ASME 2011 International Design Engineering Technical Conferences and Computers and Information in Engineering Conference. American Society of Mechanical Engineers, 1077-1086. 